\title{
Desenvolvimento de uma nova concepção geométrica para os blocos de concretos não modulares para alvenaria estrutural
}

\author{
Development of a new geometric design for non-modular \\ concrete blocks for structural masonry
}

\section{Gihad Mohamad \\ Elizabete Yukiko Nakanishi Bavastri \\ Larissa Degliuomini Kirchhof \\ Eduardo Rizzatti \\ Ana Cláudia Akele Jantsch}

Gihad Mohamad Universidade Federal de Santa Maria Santa Maria - RS - Brasil

Elizabete Yukiko Nakanishi Bavastri Universidade Tecnológica Federal do Paraná Toledo - PR - Brasil

Larissa Degliuomini Kirchhof Universidade Federal de Santa Maria Santa Maria - RS - Brasil

Eduardo Rizzatti Universidade Federal de Santa Maria Santa Maria - RS - Brasil

Ana Cláudia Akele Jantsch Universidade Federal de Santa Maria Santa Maria - RS - Brasil

Recebido em 30/09/13

Aceito em 29/01/15

\section{Resumo}

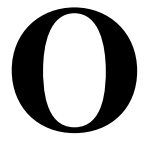

presente estudo descreve uma nova concepção geométrica para os blocos de concreto não modulares especialmente concebidos para alvenaria estrutural, com montagem capaz de permitir a superposição das paredes longitudinais e transversais dos blocos nas diferentes fiadas da parede, para facilitar o grauteamento e o posicionamento das armaduras verticais dos elementos estruturais. $\mathrm{O}$ conjunto de blocos possuem geometrias específicas para cada função, o que facilita a execução das alvenarias armadas e o aumento no desempenho estrutural e a produtividade Como geometria final, desenvolveu-se um conjunto não modular de unidades com potencial de atender aos objetivos do sistema construtivo em alvenaria estrutural.

Palavras-chaves: Alvenaria estrutural. Blocos de concreto não modulares. Concepção geométrica.

\section{Abstract}

The main goal of this study is to develop a new geometric design for non-modular concrete blocks, specifically designed for structural masonry, which allow the superposition of the face shells and cross webs for different courses in order to facilitate grouting and the placement of steel reinforcement in the vertical wall holes. The set of blocks have specific geometries for each function, which facilitate the execution of the reinforced masonry and improves structural performance and productivity. The final geometry developed is a non-modular set of units that can potentially be used in structural masonry buildings.

Keywords: Structural masonry. Concrete block. Geometric design.

MOHAMAD, G.; BAVASTRI; E. Y. N.; KIRCHHOF, L. D.; RIZZATTI, E.; JANTSCH, A. C. A. Desenvolvimento de uma nova 


\section{Introdução}

\section{Uso da alvenaria estrutural no Brasil}

A alvenaria estrutural no Brasil surgiu como uma técnica de construção apenas no final da década de 1960, pois, anteriormente, poderia ser considerada como uma "alvenaria resistente", ou seja, fruto apenas de conhecimento empírico, por consequência da inexistência de regulamentos que fixassem critérios de dimensionamento e segurança dos elementos estruturais, de forma a relacionar as diferentes tensões atuantes à resistência do elemento. A grande maioria das edificações possuía quatro pavimentos, com critérios de execução e dimensionamentos baseados na experiência do construtor. Comumente as paredes dessas edificações eram constituídas por unidades cerâmicas maciças (tijolos) nos três primeiros pavimentos, e no último pavimento eram usadas unidades vazadas com furos na direção do assentamento da parede.

O ano de 1966 datou o marco inicial do emprego do bloco de concreto vazado em alvenarias estruturais armadas no Brasil, com a construção do conjunto habitacional Central Park Lapa, em São Paulo (Figura 1a). Essa obra foi realizada com paredes de espessura de $19 \mathrm{~cm}$ e possui quatro pavimentos. Em 1972 foram construídos no mesmo conjunto habitacional 4 prédios de 12 pavimentos cada, em alvenaria armada (Figura 1b). No ano de 1970, em São José dos Campos, SP, foi construído o edifício Muriti, de 16 pavimentos em alvenaria armada de blocos de concreto (Figura 1c). $\mathrm{O}$ edifício pioneiro em alvenaria não armada no Brasil foi o Jardim Prudência, construído em São Paulo, em 1977. A edificação de 9 pavimentos em blocos de concreto silicocalcário com parede de $24 \mathrm{~cm}$ de espessura (Figura 1d).
O emprego dos blocos cerâmicos nas obras em alvenarias estruturais não armadas e armadas iniciou-se na década de 1980, com a introdução no mercado de construção de unidades com dimensões modulares e furos na vertical, que proporcionam a passagem de instalações elétricas sem os rasgos comumente feitos em obras. $\mathrm{Na}$ década de 1990 foi construído o edifício residencial Solar dos Alcântaras. Atualmente essa edificação é a maior do Brasil em alvenaria estrutural armada, com paredes de blocos de concreto com $14 \mathrm{~cm}$ de espessura do primeiro ao último andar (Figura 1e) (MORAMAD, 2015).

\section{Definições fundamentais para os projetos em alvenaria estrutural}

No sistema construtivo em alvenaria estrutural a parede é empregada para fins de transmissão de esforços, e a limitante fundamental para o lançamento é a definição das paredes estruturais e as tipologias de lajes (maciças, pré-moldadas, protendidas e alveolares). Os principais fatores condicionantes do projeto são o arranjo arquitetônico, a coordenação dimensional, a otimização do funcionamento estrutural da alvenaria e a racionalização do projeto e da produção.

São também importantes as necessidades dos clientes, os custos (incluindo aqueles de utilização e de tempo de execução), os requisitos de desempenho e os aspectos de segurança e de confiabilidade. A dificuldade da remoção de paredes, que limita a flexibilidade do processo construtivo em alvenaria estrutural, pode ser satisfatoriamente resolvida, pois o projetista estrutural, em conjunto com o arquiteto, pode especificar paredes passíveis de ser eliminadas no andar, ou seja, sem função estrutural.

Figura 1 - Prédios precursores da alvenaria estrutural construídos no Brasil

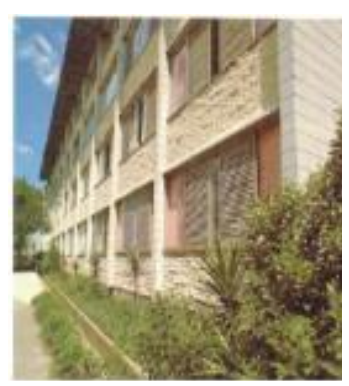

(a)

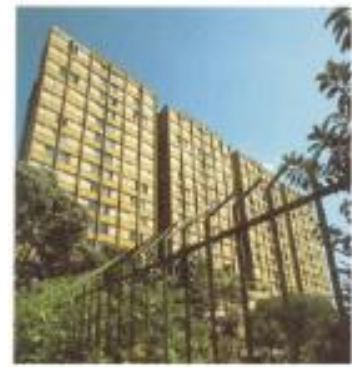

(b)

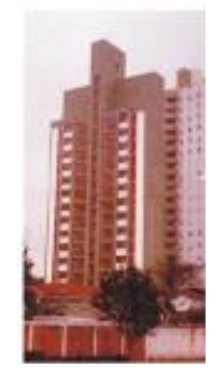

(c)

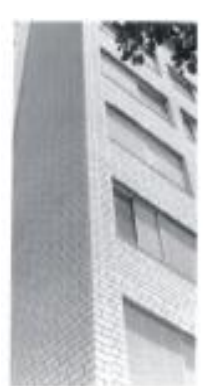

(d)

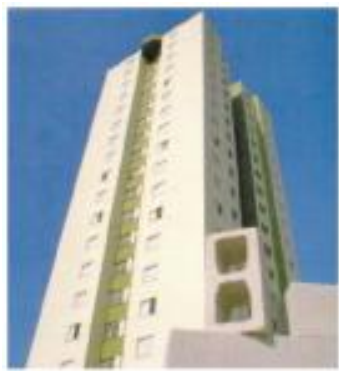

(e)

Fonte: Associação Brasileira de Construção Industrializada (1990). 
Além das condicionantes usuais de projeto, geralmente provenientes dos códigos de obra municipais, um projeto em alvenaria estrutural impõe restrições específicas aos projetistas. Entre elas se destacam as seguintes restrições estruturais:

(a) a limitação no número de pavimentos da edificação, devido aos limites das resistências dos materiais disponíveis no mercado;

(b) o arranjo espacial das paredes estruturais e a necessidade de amarração entre os elementos;

(c) o comprimento e a altura dos painéis de paredes estruturais, que pode afetar a esbeltez do elemento e a presença de juntas de movimentação;

(d) as limitações quanto à existência de transição para as estruturas em pilotis no térreo ou em subsolos;

(e) a impossibilidade de remoção posterior das paredes estruturais;

(f) o uso de balanços, principalmente de sacadas que provocam torção; e

(g) a necessidade das passagens das instalações sob pressão (hidráulicas e de gás) em espaços previamente pensados, sem rasgos dos elementos estruturais.

\section{Vantagens econômicas do processo em alvenaria estrutural}

As constantes dificuldades devido ao aumento gradual da concorrência e dos níveis de exigência construtiva têm provocado nas empresas construtoras uma mudança nas estratégias, de forma a possibilitar a introdução de melhorias na produção, empregando alternativas que levem à racionalização do processo. A principal pergunta das empresas construtoras em geral é como garantir a habitabilidade e o desempenho do ambiente construído. Essa pergunta é fundamental para entender o atual cenário brasileiro, devido ao aumento do número de créditos para as construções de habitações. Por isso, a alvenaria estrutural está sendo largamente utilizada como sistema construtivo capaz de responder à pergunta acima, pois é capaz de atender aos critérios de desempenho e custo.

A alvenaria estrutural possui diversas vantagens, e a econômica é uma das principais, devido à otimização de tarefas na obra, por meio de técnicas executivas simplificadas e facilidade de controle nas etapas de produção e eliminação de interferências, o que gera diminuição no desperdício de materiais produzidos pelo constante retrabalho. Como consequência, o sistema construtivo em alvenaria estrutural conseguiu proporcionar flexibilidade no planejamento das etapas de execução das obras. Isso tornou o sistema em alvenaria competitivo no Brasil, quando comparado com o concreto armado e o aço (ROMAN et al., 1998).

\section{Inovações empreendidas no sistema construtivo em alvenaria estrutural}

Franco (1996) destaca que as implantações de inovações na construção civil devem estar baseadas em análises feitas por meio de metodologias científicas, fundamentadas em critérios de construtibilidade e desempenho, para que permitam transpor barreiras de produtividade e custo.

Atualmente, existem no mercado da construção civil brasileiro diferentes alternativas tecnológicas, com a introdução de uma variedade de materiais, ferramentas e técnicas construtivas de montagem a seco que visam, principalmente, aumentar a produção e diminuir o desperdício de materiais e mão de obra.

$\mathrm{Na}$ alvenaria estrutural, que é o caso deste estudo, não houve mudança significativa em termos de formato geométrico e disposição dos componentes ao longo do tempo, principalmente para os blocos de concretos não modulares. As experiências de inovação existentes dizem respeito ao sistema estrutural, e não à unidade. Como exemplo de inovação na alvenaria estrutural, pode-se citar a produção de painéis em alvenaria ou concreto, cuja finalidade maior é o aumento do ritmo de produção, como os painéis funcionais, que visam industrializar o elemento estrutural parede em alvenaria para habitações unifamiliares e multifamiliares, desenvolvidos pela empresa Edifficaz Tecnologia em Construção, e o emprego de blocos de construção em EPS vazados, sendo uma fôrma para, posteriormente, ser preenchida por concreto autoadensável, constituindo uma parede estrutural em concreto armado, como mostra a Figura 2. Por isso, existe a necessidade de estudos de novos componentes estruturais que facilitem a execução e o desempenho, diminuindo significativamente o consumo de concreto e armadura, no intuito de tornar a construção sustentável e com o menor desperdício possível. 
Figura 2 - Sistema em bloco EPS

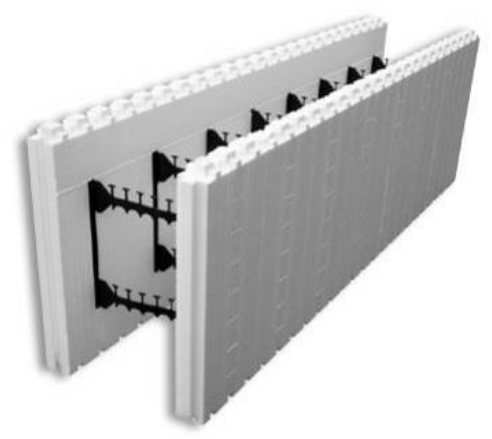

Fonte: Quero Construir (2013).

\section{Temática a ser abordada}

\section{Definição de norma para os blocos de concreto}

No Brasil se produzem blocos de concreto com as características físicas e mecânicas recomendadas pelas normativas da NBR 6136 (ABNT, 2014). Por definição, o termo "bloco vazado" é empregado quando a unidade possui área líquida igual ou inferior a $75 \%$ da área bruta. As unidades são especificadas de acordo com suas dimensões nominais, ou seja, dimensões comerciais indicadas pelos fabricantes, múltiplas do módulo $\mathrm{M}=10 \mathrm{~cm}$ e seus submódulos $2 \mathrm{M}$ x $2 \mathrm{M}$ x $4 \mathrm{M}$ (largura $\mathrm{x}$ altura $\mathrm{x}$ comprimento). As unidades de concreto são definidas a partir de suas dimensões nominais especificadas pelo fabricante para largura, altura e comprimento (exemplo: 190 mm x 190 mm x 390 $\mathrm{mm}$ ), e as medidas reais verificadas diretamente no bloco (exemplo: $192 \mathrm{~mm}$ x $193 \mathrm{~mm}$ x $393 \mathrm{~mm}$ ). A NBR 6136 (ABNT, 2014) fixa os requisitos para a classificação dos blocos vazados de concreto simples destinados à alvenaria com ou sem função estrutural. As classificações gerais de uso das unidades são:

(a) Classe A: blocos com função estrutural, para uso em elementos de alvenaria acima ou abaixo do nível do solo;

(b) Classe B: blocos com função estrutural, para uso em elementos de alvenaria acima do nível do solo; e

(c) Classe C: blocos com e sem função estrutural, para uso em elementos de alvenaria acima do nível do solo ${ }^{1}$.

Os blocos de concreto devem apresentar as propriedades a seguir.

${ }^{1}$ Os blocos da classe $\mathrm{C}$ com função estrutural, com largura de 90 $\mathrm{mm}$, podem ser usados para edificações de no máximo um pavimento; os blocos de $115 \mathrm{~cm}$ de largura, para edificações de no máximo dois pavimentos; e os de $140 \mathrm{~mm}$ e de $190 \mathrm{~mm}$ de largura, para edificações de no máximo cinco pavimentos.

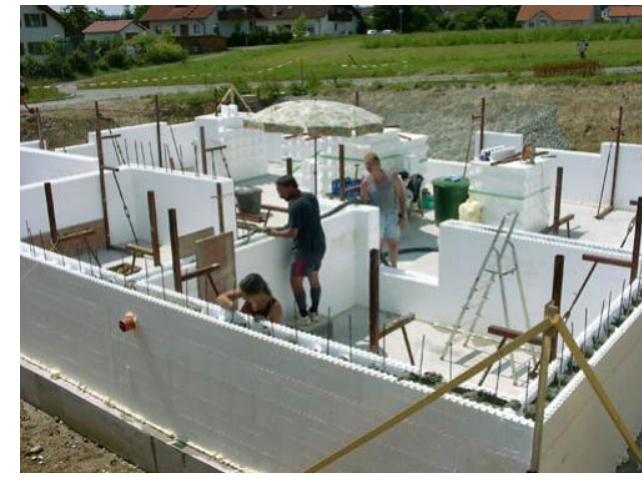

\section{Aspecto}

Os blocos devem apresentar aspecto homogêneo, ser compactos, ter arestas vivas e ser livres de trincas ou outras imperfeições que possam prejudicar seu assentamento, ou as características mecânicas e de durabilidade da edificação.

\section{Dimensões}

Os blocos de concreto devem atender às dimensões estabelecidas no contrato entre fornecedor $\mathrm{e}$ comprador. Caso isso não ocorra, poderá ficar comprometida tanto a modulação prevista na fase de projeto quanto a racionalização do processo construtivo. Pequenos desvios dimensionais podem ser aceitos, desde que estejam dentro dos limites estabelecidos pela NBR 6136 (ABNT, 2014), conforme a Tabela 1. As dimensões reais dos blocos vazados de concreto, modulares e submodulares, devem corresponder às dimensões constantes na Tabela 2 .

A espessura mínima de qualquer parede do bloco deve atender à Tabela 3, na qual a tolerância das medidas permitidas é de $\pm 1,0 \mathrm{~mm}$ para cada valor individual.

\section{Características gerais do sistema em alvenaria de blocos tradicional}

A alvenaria estrutural é um sistema construtivo cuja unidade básica de construção é o bloco, e o principal elemento resistente é a parede. Essas unidades podem ser feitas com diferentes materiais, como cerâmica, concreto, silicocalcário e concreto celular. Os blocos estruturais se diferenciam por suas dimensões e podem ser classificadas como unidades modulares e não modulares, conforme a proporção entre a largura e o comprimento. Os blocos de concreto encontrados normalmente no mercado da construção civil são da família de $15 \mathrm{~cm}$ x $30 \mathrm{~cm}$ ou de $15 \mathrm{~cm}$ x $40 \mathrm{~cm}$ (dimensão nominal). Os blocos da família $15 \mathrm{~cm} \mathrm{x}$

130 Mohamad, G.; Bavastri, E. Y. N.; Kirchhof, L. D.; Rizzatti, E.; Jantsch, A. C. A. 
$40 \mathrm{~cm}$ possuem dimensões não modulares em função de as relações entre o comprimento e a largura não serem o dobro. A Figura 3 mostra as imagens dos blocos de concretos não modulares da família de $15 \mathrm{~cm}$ x $40 \mathrm{~cm}$ encontrados no mercado brasileiro e seus blocos especiais para as respectivas amarrações entre as paredes. As dimensões apresentadas na Figura 3 são dimensões nominais em centímetros. Quanto ao aspecto geométrico, esses blocos possuem paredes longitudinais e transversais maciças, e disposição regular dos furos, com exceção do bloco especial de amarração em "L" de comprimento nominal de $35 \mathrm{~cm}$ e real de $34 \mathrm{~cm}$. Nesse tipo de sistema estrutural, a segurança global das construções é garantida pela disposição das paredes estruturais e as amarrações entre estas, garantindo, assim, a estabilidade lateral em todas as direções e a transmissão dos esforços oriundos do peso próprio e do vento. As amarrações entre as paredes são garantidas pelos blocos especiais, sendo esses os grandes responsáveis pela vinculação e o enrijecimento dos elementos estruturais.

A Figura 4 apresenta duas formas de amarração entre as paredes em L, com blocos da família 15 $\mathrm{cm}$ x $40 \mathrm{~cm}$. No primeiro caso da Figura $4 \mathrm{se}$ utilizaram dois blocos especiais de $35 \mathrm{~cm}$ de comprimento nominal na primeira e segunda fiadas, para a amarração em L. No segundo caso se empregou um compensador dimensional de $5 \mathrm{~cm} \mathrm{e}$ um bloco especial de $35 \mathrm{~cm}$ na segunda fiada para uma amarração a $50 \%$.

Tabela 1 - Tolerâncias máximas de fabricação

\begin{tabular}{c|c}
\hline Dimensão & Tolerância (mm) \\
\hline Largura (L) & \pm 2 \\
Altura (H) & \pm 3 \\
Comprimento (C) & \pm 3 \\
\hline
\end{tabular}

Fonte: NBR 6136 (ABNT, 2014).

Tabela 2 - Dimensões nominais dos blocos

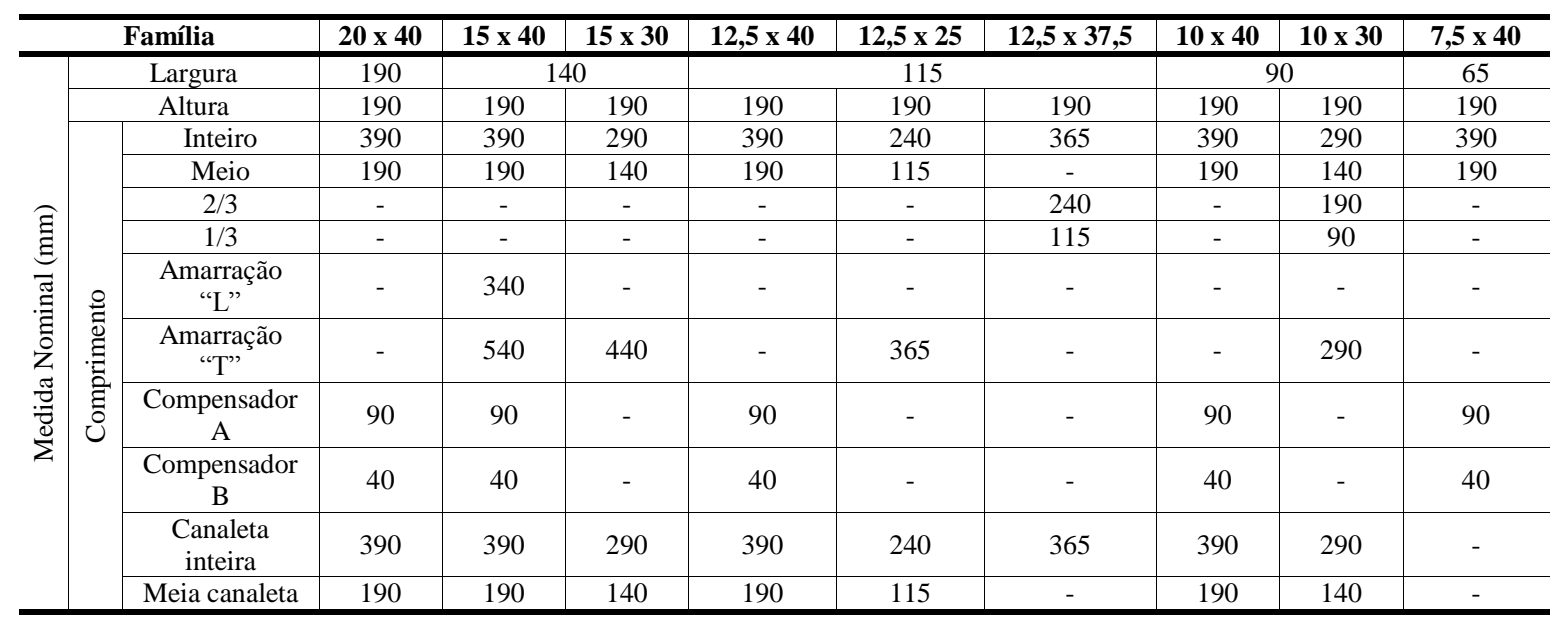

Fonte: NBR 6136 (ABNT, 2014). 
Tabela 3 - Designação por classe, largura dos blocos e espessura mínima das paredes dos blocos

\begin{tabular}{|c|c|c|c|c|}
\hline \multirow[b]{2}{*}{ Classe } & \multirow{2}{*}{$\begin{array}{c}\text { Largura } \\
\text { nominal } \\
\text { mm } \\
\end{array}$} & \multirow{2}{*}{$\begin{array}{c}\text { Paredes } \\
\text { longitudinais }^{\mathrm{a}} \\
\mathbf{m m} \\
\end{array}$} & \multicolumn{2}{|c|}{ Paredes transversais } \\
\hline & & & Paredes $^{\text {a }}(\mathrm{mm})$ & $\begin{array}{c}\text { Espessura } \\
\text { equivalente }^{\mathrm{b}}(\mathrm{mm})\end{array}$ \\
\hline \multirow{2}{*}{ A } & 190 & 32 & 25 & 188 \\
\hline & 140 & 25 & 25 & 188 \\
\hline \multirow{2}{*}{ B } & 190 & 32 & 25 & 188 \\
\hline & 140 & 25 & 25 & 188 \\
\hline \multirow{5}{*}{$\mathrm{C}$} & 190 & 18 & 18 & 135 \\
\hline & 140 & 18 & 18 & 135 \\
\hline & 115 & 18 & 18 & 135 \\
\hline & 90 & 18 & 18 & 135 \\
\hline & 65 & 15 & 15 & 113 \\
\hline
\end{tabular}

Fonte: NBR 6136 (ABNT, 2014).

Nota: Legenda:

${ }^{\text {a }}$ Média das medidas das paredes tomadas no ponto mais estreito; e

${ }^{\mathrm{b}}$ Soma das espessuras de todas as paredes transversais aos blocos (em milímetros), dividida pelo comprimento nominal do bloco (em metros).

Figura 3 - Blocos de concreto estruturais da família $15 \mathrm{~cm}$ x $40 \mathrm{~cm}$

19

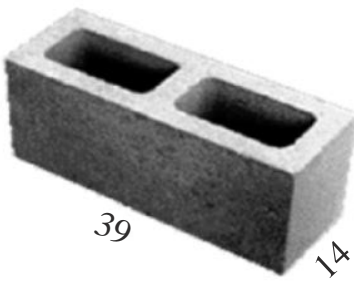

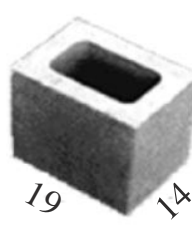

Figura 4 - Encontros de paredes estruturais em $\mathrm{L}$

\section{Amarração em L}

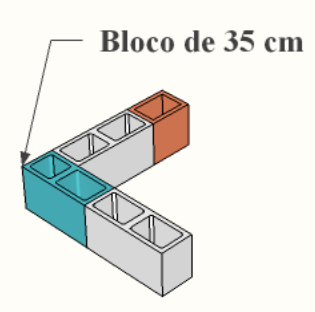

Primeira Fiada
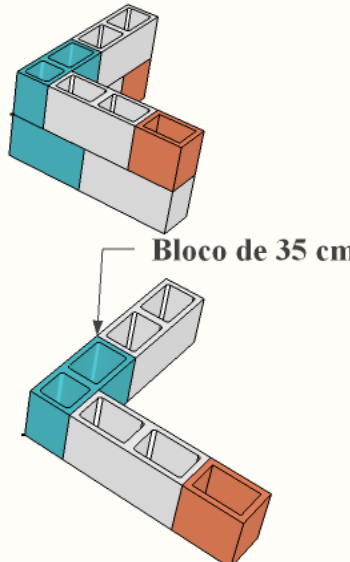

Segunda Fiada

A Figura 5 mostra a execução das amarrações em "T", onde são necessários blocos especiais de 55 $\mathrm{cm}$ na primeira fiada e de $35 \mathrm{~cm}$ na segunda, ou vice-versa. As formas possíveis de amarrações são dependentes das unidades que as indústrias produzem. Como exemplo, é mostrada uma segunda condição para a amarração em $\mathrm{T}$ sem

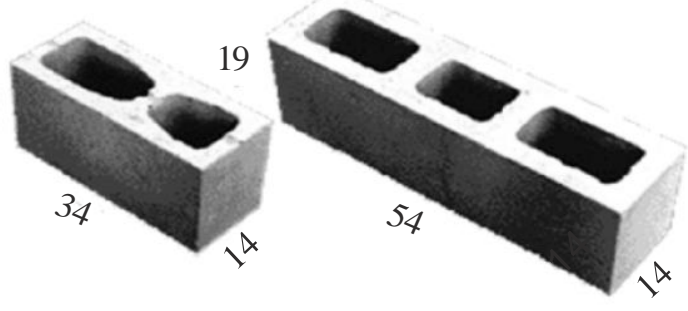

Amarração em L

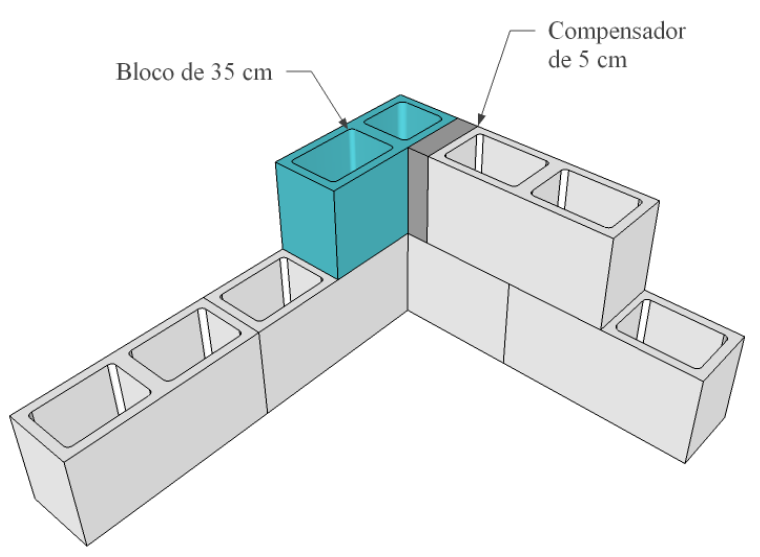

empregar o bloco de $35 \mathrm{~cm}$, desde que se use um compensador de $5 \mathrm{~cm}$ de largura, como mostra a Figura 6(a). Na amarração em cruz ("X") é necessária a utilização do bloco de $55 \mathrm{~cm}$ de comprimento na primeira e segunda fiadas, para amarrar as juntas entre os blocos a $50 \%$ do comprimento deles, como mostra a Figura 6(b). 
Para explicar melhor o contexto principal das modificações geométricas dos blocos, é importante apresentar algumas definições. Paredes longitudinais são as paredes no sentido do comprimento do bloco, e paredes transversais são as paredes no sentido da largura do bloco, como mostra a Figura 7.

Figura 5 - Encontros de paredes estruturais em T

\section{Amarração em T}

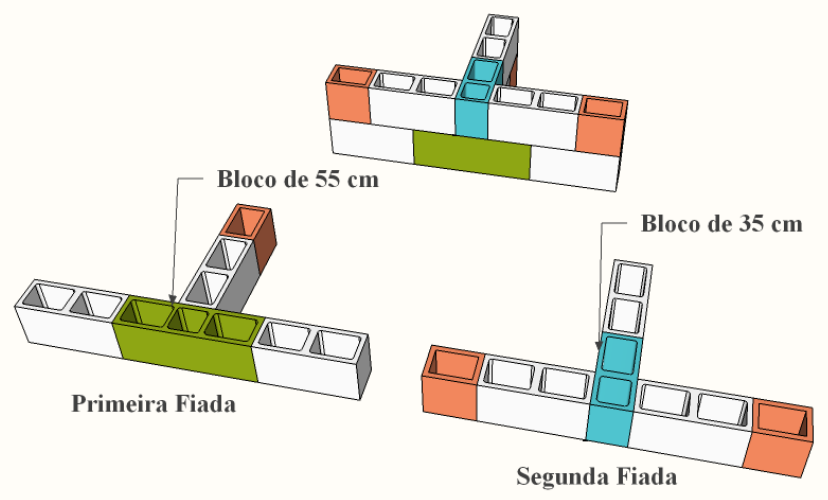

Figura 6 - Encontros de paredes estruturais em cruz

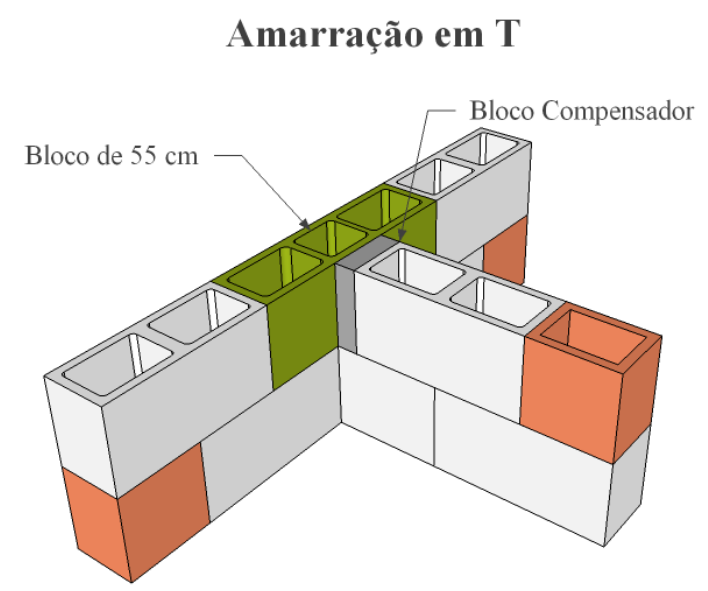

(a)

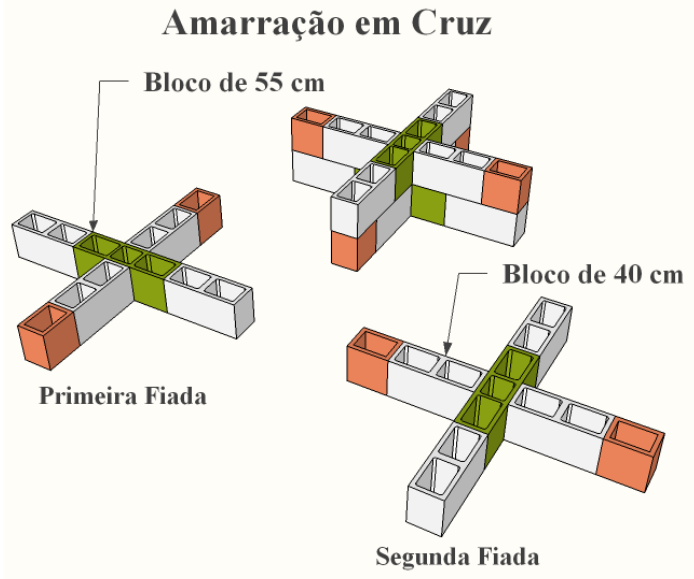

(b)

Figura 7 - Nomenclatura das paredes dos blocos estruturais

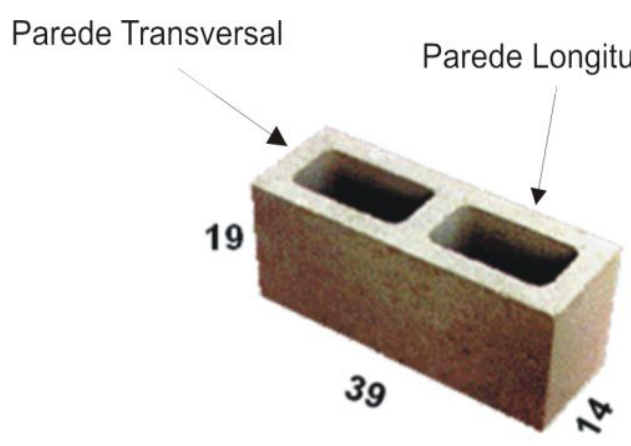


No sistema construtivo em alvenaria estrutural as paredes são o principal elemento por onde, nos cálculos, é definido o tipo de bloco a partir de sua resistência característica. As paredes são a união entre os blocos e as argamassas intercaladas nas diferentes fiadas.

Como mostrado anteriormente, as amarrações são fundamentais para a integridade estrutural da construção. Mesmo uma amarração a 50\% não garante que todas as paredes transversais se apoiem umas sobre as outras. A disposição dos blocos nas diferentes fiadas das alvenarias pode gerar alguns inconvenientes devido ao fato de as espessuras da parede transversal intermediária do bloco nas fiadas inferiores e superiores não coincidirem, ou seja, as paredes transversais do bloco nas fiadas inferiores podem ficar no ar, e não se apoiar. Com isso, as tensões não são transmitidas de forma uniforme ao longo de toda a seção do bloco, reduzindo o potencial resistente da parede, como mostra a Figura 8. Por consequência, o meio técnico opta, muitas vezes, pela retirada da argamassa de assentamento da parede transversal do bloco e assenta apenas nas paredes longitudinais.

A própria norma brasileira sobre alvenaria estrutural de bloco de concreto NBR 15961-1 (ABNT, 2011a) considera que, se as juntas horizontais tiverem argamassamento parcial (apenas sobre as paredes longitudinais dos blocos) e se a resistência for determinada com base no ensaio de prisma ou pequena parede, moldados com a argamassa aplicada em toda a área líquida dos blocos, a resistência característica à compressão simples da alvenaria deve ser corrigida pelo fator 0,80. Portanto, o objetivo dessa invenção é desenvolver uma nova geometria para os blocos estruturais focando no desempenho do elemento construtivo produzido pela coincidência das paredes transversais do bloco, a fim de aumentar as características à compressão e facilitar a execução dos encontros armados. Além da unidade básica são apresentados todos os componentes especiais necessários para o sistema estrutural, bem como as amarrações das paredes em L e T, com e sem a presença da gola das portas, ou seja, os itens necessários para a execução do sistema construtivo.

\section{Campo da inovação Definição}

As modificações geométricas dos blocos estruturais não modulares da família $15 \mathrm{~cm} \mathrm{x} 40$ $\mathrm{cm}$ têm por objetivo permitir o emprego com a total sobreposição das paredes longitudinais e transversais das unidades nas diferentes fiadas e formar colunas uniformes de grautes nos encontros entre os elementos estruturais. Essas melhorias garantem maior integridade do elemento estrutural e capacidade de absorver os esforços de compressão. Sendo assim, a presente inovação é centrada nas disposições geométricas das paredes longitudinais e transversais do bloco, e na consequente melhoria do processo de execução da alvenaria armada, devido à ausência de uma das paredes laterais do bloco, item que facilita o encaixe da armadura vertical sem a necessidade de erguê-lo para o encaixe do reforço.

Resultados experimentais prévios por intermédio de ensaios em paredes de blocos demonstraram que as superposições das paredes longitudinais e transversais aumentam a área resistente e, de certa forma, poderiam auxiliar no ganho potencial de resistência da parede (RIZZATTI et al., 2012). Também, ensaios experimentais em pequenas paredes de blocos de concreto demonstraram que as fissurações desses elementos estruturais aconteceram nas regiões próximas às paredes transversais do bloco, gerado pela falta de coincidência dos septos transversais (MOHAMAD; LOURENÇO; ROMAN, 2011).

Na Figura 9 visualiza-se a distribuição das fissuras (frente e verso) na parede com blocos tradicionais, que, para uma melhor classificação, foram designados pelos tipos 1, 2, 3 e 4 . As fissuras do tipo 1 foram provocadas pela abertura da junta vertical, falta de apoio das paredes transversais e o consequente esmagamento da argamassa (normalmente esse tipo de fissura acontece quando a relação tensão/resistência atinge 0,60 ); as do tipo 2 são fissuras de tração que cortam as faces do bloco (essas fissuras, normalmente, são as continuidades da fissura do tipo 1 e acontecem quando a relação tensão/resistência atingir 0,80 a 0,90); as do tipo 3 são os esmagamentos localizados da argamassa horizontal (acontecem em simultâneo com as fissuras do tipo 2); e as fissuras do tipo 4 são de descolamento horizontal entre o bloco e a argamassa (provocado por rotação na parede e o consequente desprendimento do contato entre a junta e o bloco). As fissuras foram simétricas em ambos os lados da parede, ou seja, não se verificou que as fissuras horizontais fossem de flexão. Dos ensaios de pequenas paredes pode-se destacar as seguintes observações: a importância de as amostras terem as mesmas condições de fronteira, ou seja, o número de juntas verticais ser igual na primeira e última fiada; no decorrer dos ensaios e na análise dos resultados, verificou-se que a alvenaria (bloco e argamassa) tende a igualar a rigidez dos materiais, ou seja, por mais diferente que seja a resistência do bloco e da

134 Mohamad, G.; Bavastri, E. Y. N.; Kirchhof, L. D.; Rizzatti, E.; Jantsch, A. C. A. 
argamassa, parece que a junta de argamassa horizontal e o bloco passam a comportar-se como únicos; o ponto fraco do conjunto é justamente o encontro entre a parede transversal e a junta vertical de argamassa, onde o processo de ruptura acontece.

A partir dessas análises, iniciaram-se os estudos sobre um novo padrão geométrico para os blocos estruturais, tendo por base a coincidência de todas as paredes do bloco para aumentar o desempenho à compressão. As melhorias no formato geométrico do bloco proporcionam facilidades aos procedimentos executivos de paredes estruturais, principalmente as armadas e grauteadas.

\section{Levantamento de anterioridade da geometria de blocos}

Foram realizadas buscas de anterioridades em patentes tecnológicas de desenvolvimento de produtos para a construção civil, a fim de criar uma base de análise, pois em termos de artigos técnicos em periódicos não se encontrou material sobre os aspectos técnicos e tecnológicos de desenvolvimento de produtos para os blocos estruturais.

\section{Patentes levantadas}

A Figura 10 apresenta uma patente de bloco para a construção de muros de arrimo e seu método de construção. A geometria do bloco é caracterizada por possuir duas paredes longitudinais e uma parede transversal entre as paredes longitudinais; cada parede longitudinal possui reentrâncias dispostas nas laterais do bloco, que formam um sistema de encaixes entre as unidades. $\mathrm{O}$ melhoramento proporcionado pela nova geometria permite a execução das alvenarias sem a utilização da argamassa de assentamento na junta vertical devido ao sistema de encaixe.

\section{Figura 8 - Vista frontal da parede estrutural}

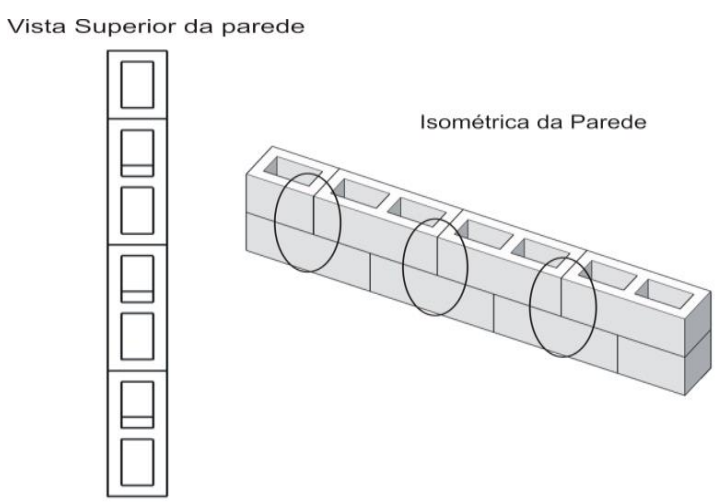

Figura 9 - Parede de $1 \mathrm{~m}$ por $1 \mathrm{~m}$, modo de ruptura

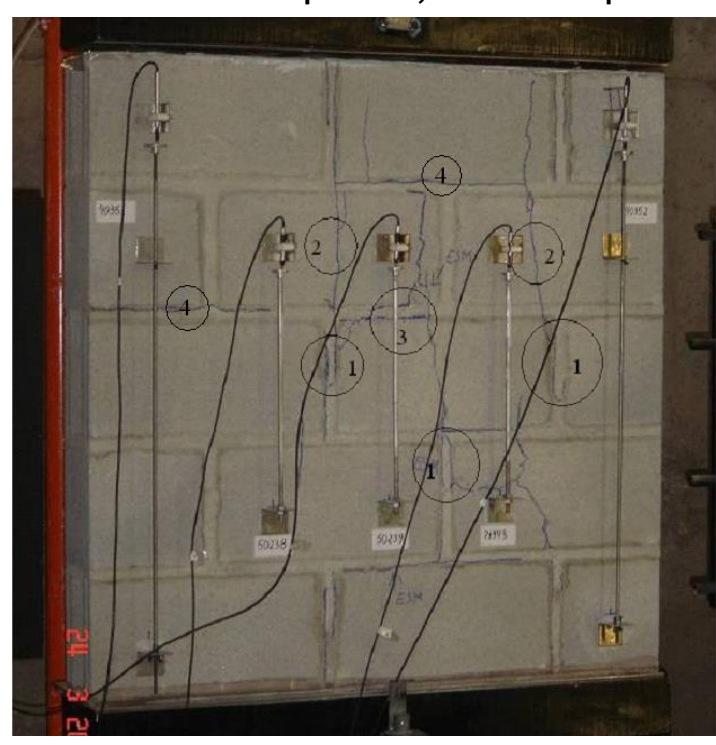

Frente

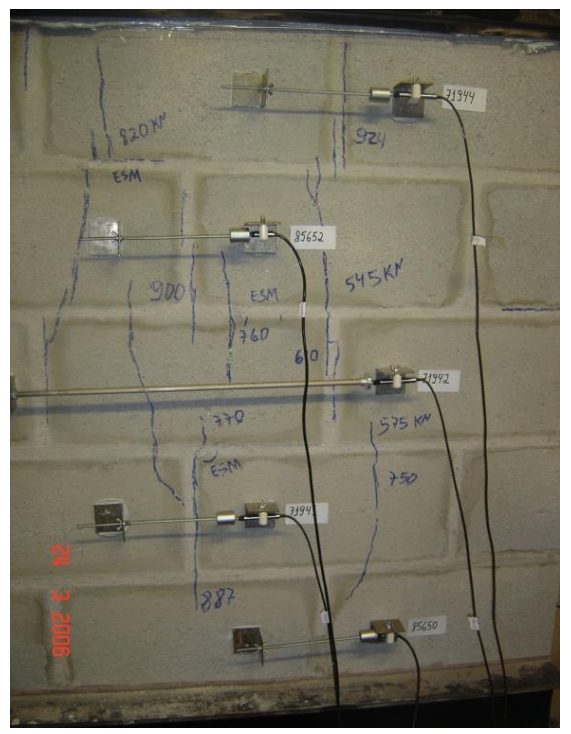

Verso 
Figura 10 - Vistas do bloco - Patente: AU2011101173 A4: IMPROVED MASONRY BLOCK - Data:

\section{$13 / 10 / 2011$}

\section{Vista superior}

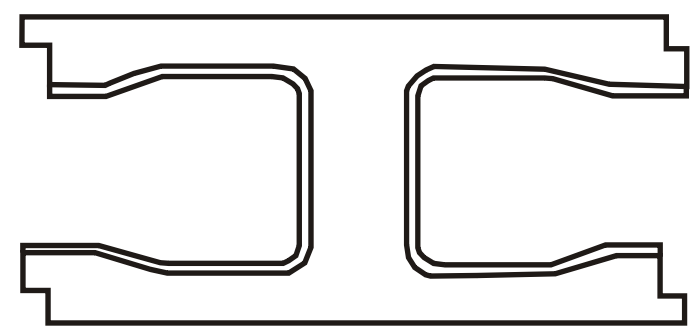

A Figura 11 apresenta uma patente de invenção, cujos blocos foram desenvolvidos para a construção de paredes estruturais e muros de arrimo. O bloco possui aberturas internas que permitem a concretagem vertical, horizontal e o posicionamento das armaduras das paredes nas duas direções (vertical e horizontal). Além disso, existem saliências que permitem seu encaixe, de forma a evitar o deslocamento horizontal durante a concretagem.

A Figura 12 apresenta a patente de modelo de utilidade para os blocos estruturais, compreendido por quatro modelos de blocos de concreto, sendo o bloco padrão com um furo e com dimensões de 14 cm x $14 \mathrm{~cm}$ de seção e $19 \mathrm{~cm}$ de altura; o bloco com dois furos, com dimensões de $14 \mathrm{~cm}$ x $29 \mathrm{~cm}$ de seção e $19 \mathrm{~cm}$ de altura; o bloco com três furos, com dimensões de $14 \mathrm{~cm}$ x $44 \mathrm{~cm}$ de seção e 19 $\mathrm{cm}$ de altura; e o bloco com quatro furos, com as dimensões de $14 \mathrm{~cm}$ x $59 \mathrm{~cm}$ de seção e $19 \mathrm{~cm}$ de altura. Essa patente de modelo de utilidade é caracterizada pelo fato de os blocos de dois furos (2), três furos (3) e quatro furos (4) terem seus comprimentos múltiplos do bloco padrão de um furo (1), o que permite a modulação das peças na concepção de uma alvenaria de blocos de concreto simples e possibilita, segundo os autores, a

\section{Vista frontal}

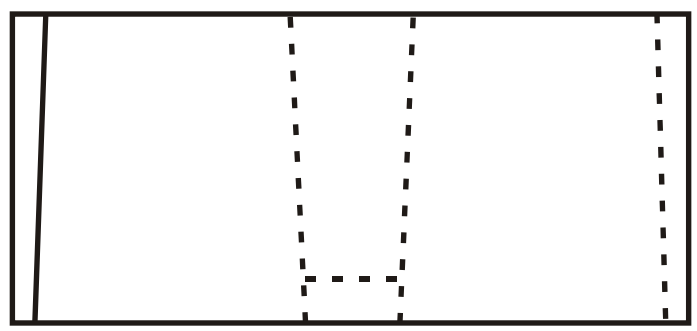

redução de custos e o aumento do rendimento da produção.

A Figura 13 apresenta um modelo de bloco de concreto que se caracteriza por conjugar as funções de aprumar e alinhar as paredes sem a necessidade de utilização de argamassa, linha ou prumo. Os blocos de concreto intertravados possuem um sistema de encaixe inovador que dispensa a utilização de argamassa entre eles para sua fixação. Segundo os autores, a unidade proporciona melhor desempenho e, consequentemente, gera uma economia substancial de material a ser empregado quando do acabamento. Além disso, o bloco apresenta orifícios por onde poderão passar os cabeamentos elétricos e hidráulicos, sem a necessidade de se cortarem as paredes. Os autores citam que o bloco de concreto com encaixes intertravados é fabricado com materiais resistentes, por meio de uma fôrma de metal, fechado na horizontal superior e em suas verticais, onde o concreto é colocado e vibrado.

A Figura 14 apresenta a patente de modelo de utilidade para "Bloco de concreto". O modelo refere-se a um bloco de concreto que apresenta encaixes superiores, inferiores e laterais, do tipo macho e fêmea, que poderão ser utilizados na construção civil sem a utilização de argamassas.

136 Mohamad, G.; Bavastri, E. Y. N.; Kirchhof, L. D.; Rizzatti, E.; Jantsch, A. C. A. 
Figura 11 - Vista da geometria do bloco - Patente: AU2010101458 A4: AN INTERLOCKING CORNER MASONRY BLOCK - Data: 03/02/2011
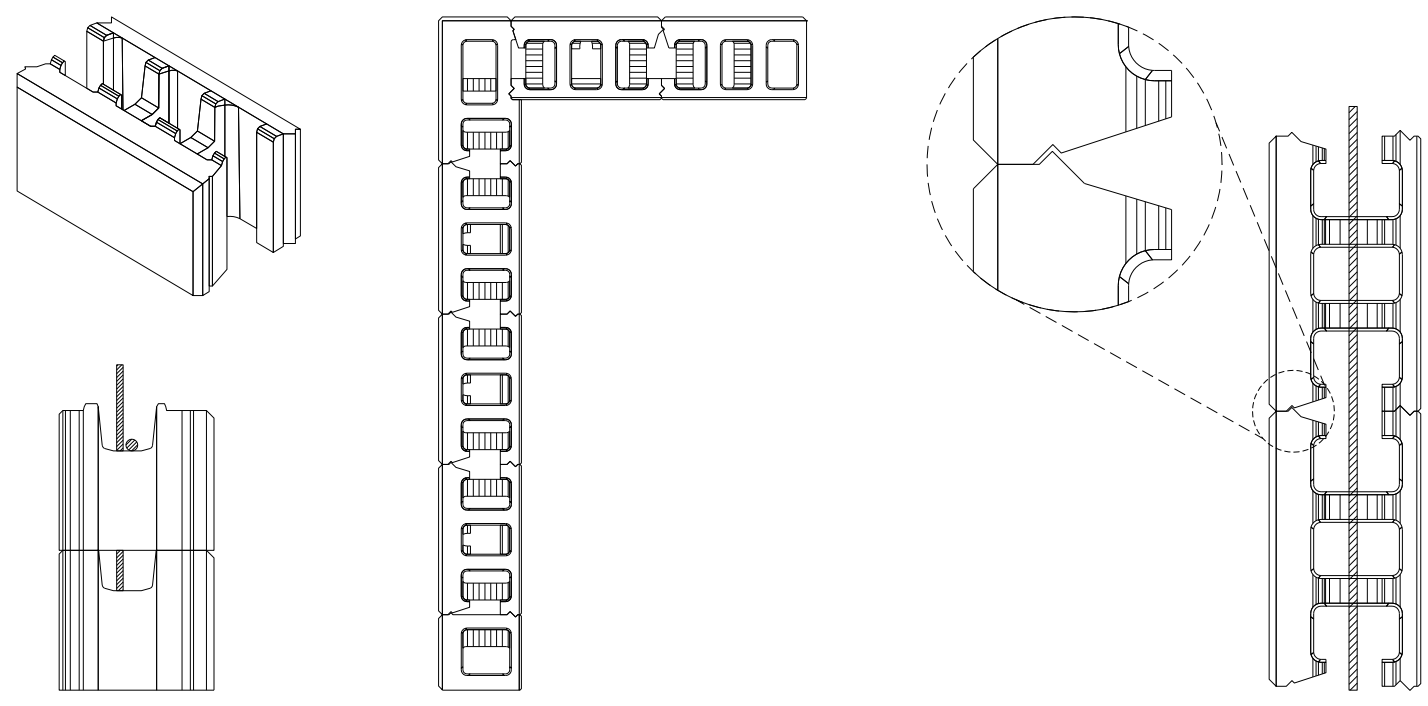

Figura 12 - Vista da geometria do bloco - Patente MU 8801919-5 U2: BLOCOS ESTRUTURAIS DE CONCRETO SIMPLES - Data de depósito: 08/09/2008

1

2

3

4

Figura 13 - Vista da geometria do bloco - Patente MU 9000066-8 U2: BLOCOS DE CONCRETO COM ENCAIXES INTERTRAVADOS - Data de depósito: 14/01/2010
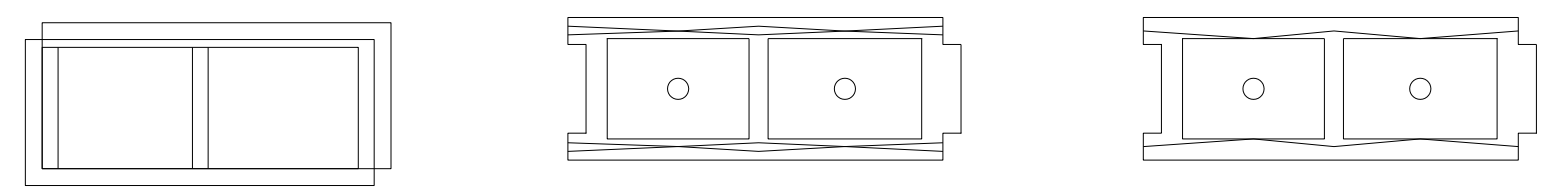

Figura 14 - Vista da geometria do bloco - Patente MU 7500705-3 U: BLOCO DE CONCRETO - Data de depósito: 27/03/1995
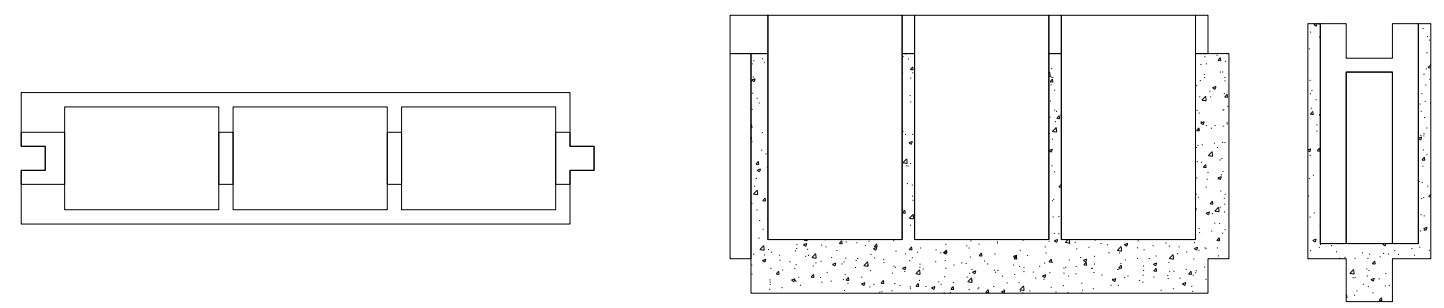
A Figura 15 apresenta os blocos de concreto para a construção de muros e paredes residenciais, industriais e construção civil em geral. Os autores destacam que as unidades permitem rapidez de execução, dispensam reboco, mantêm a obra limpa e evitam desperdícios. Diferenciam-se dos demais pré-moldados existentes no mercado por terem canais para alojamento do aço, que posteriormente servirão de amarração na união dos blocos de concreto, proporcionando rápida montagem na obra e dispensando acabamentos.
Os blocos da Figura 16 podem ser empregados em alvenaria de vedação, alvenaria estrutural e outros campos possíveis de utilização na construção civil em geral. Os blocos de concreto confeccionados são dotados de um sistema de encaixe, sendo necessário o uso de argamassa. Segundo os autores, a patente é caracterizada pelo fato de possuir um "sistema de travamento" no sentido vertical, o que possibilita diminuição no custo da alvenaria e aumento da produtividade, pois elimina o trabalho de "prumo" do bloco e elimina a argamassa da junta vertical.

Figura 15 - Vista da geometria do bloco - Patente MU 8601606-7 U: BLOCO DE CONCRETO MACIÇO COM CANAIS - Data de depósito: 06/07/2006

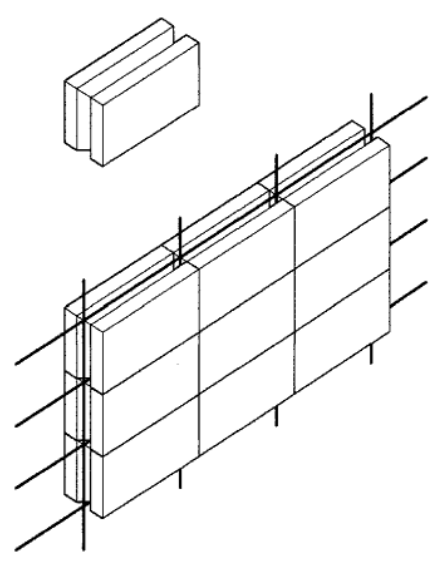

Figura 16 - Vista da geometria do bloco - Patente MU 8601606-7 U: BLOCO DE CONCRETO MACIÇO COM CANAIS - Data de depósito: 06/07/2006
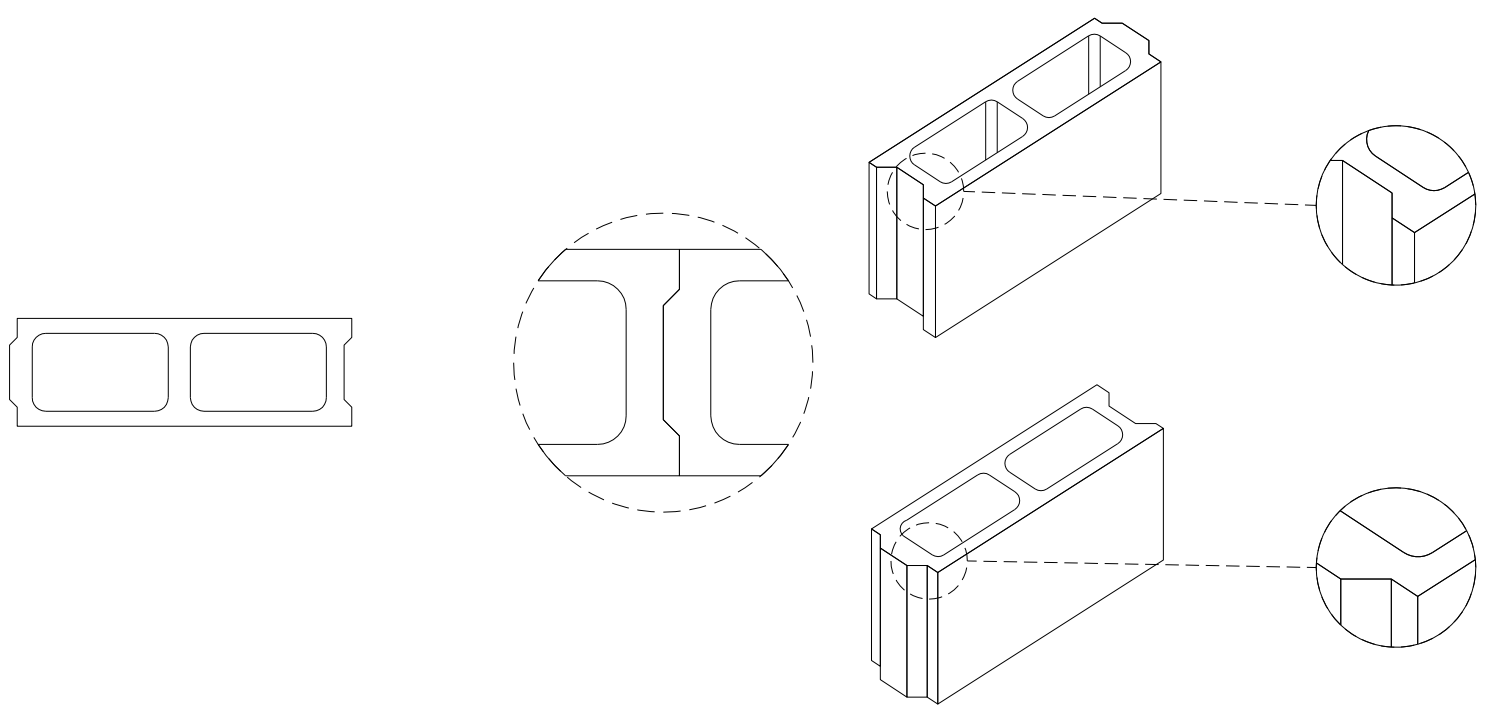

138 Mohamad, G.; Bavastri, E. Y. N.; Kirchhof, L. D.; Rizzatti, E.; Jantsch, A. C. A. 
A invenção mostrada na patente PI 0711693-4 A2, na Figura 17, refere-se a um bloco de construção que tem saliências e reentrâncias nas faces superior e inferior, o que permite o encaixe total das superfícies entre os blocos. As paredes transversais dos blocos nas fiadas superiores se apoiam nos espaços deixados entre as saliências.

A Figura 18 é uma patente que se refere a elementos estruturais e materiais de construção com unidades desenvolvidas para melhorar o desempenho térmico da construção, compostos de uma unidade de canto com reentrâncias que permite o encaixe das unidades e blocos côncavos, que vão se entrelaçando e dando a espessura final da parede.

A Figura 19 apresenta uma patente de invenção para uso em alvenaria estrutural com blocos de canto côncavo. Os blocos de canto côncavo são combinados com blocos em forma de "I" vazados e são divididos em blocos de um único côncavo de canto e blocos de duplo côncavo de canto. Durante o processo de execução da alvenaria de canto, os blocos de um único côncavo e os blocos de duplo côncavo são escalonados, uns em relação aos outros, ao longo da altura, o que impede a superposição das juntas verticais de argamassa e garante a estabilidade da parede. Segundo os autores, os blocos de canto côncavo e o método de execução das alvenarias trazem efeitos positivos em função de melhorar a estabilidade da ligação entre uma parede e um canto.

A Figura 20 descreve uma patente desenvolvida para um sistema de parede de alvenaria que inclui uma pluralidade de blocos. Cada bloco tem duas saliências laterais em faces opostas e é adaptado para usá-las em combinação com outros blocos na parte inferior da fiada, alinhando as saliências e formando diferentes composições. Basicamente essas unidades são usadas para fins decorativos ou estéticos.

Figura 17 - Vista da geometria do bloco - Patente PI 0711693-4 A2: MELHORAS RELACIONADAS COM UM BLOCO OCO DE ALVENARIA DE CONCRETO - Data de depósito: 10/05/2007
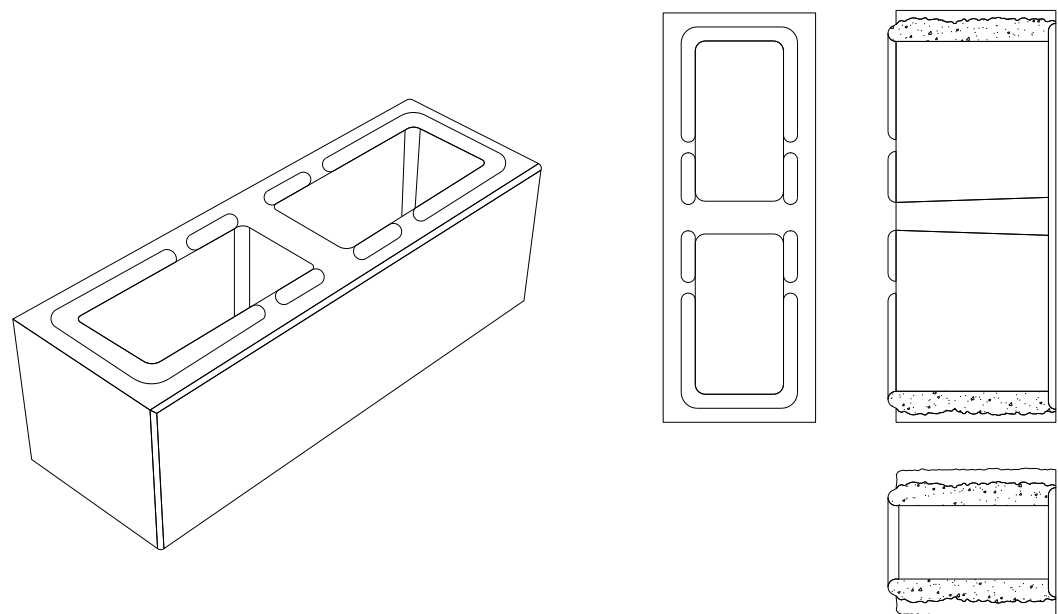
Figura 18 - Vista da geometria das unidades - Patente CN 102296740: A GRIPS BUILDING BLOCK AND BUILDING METHOD OF POROUS CORNER OF THE MAKING MOULD - Data de depósito: 13/05/2011
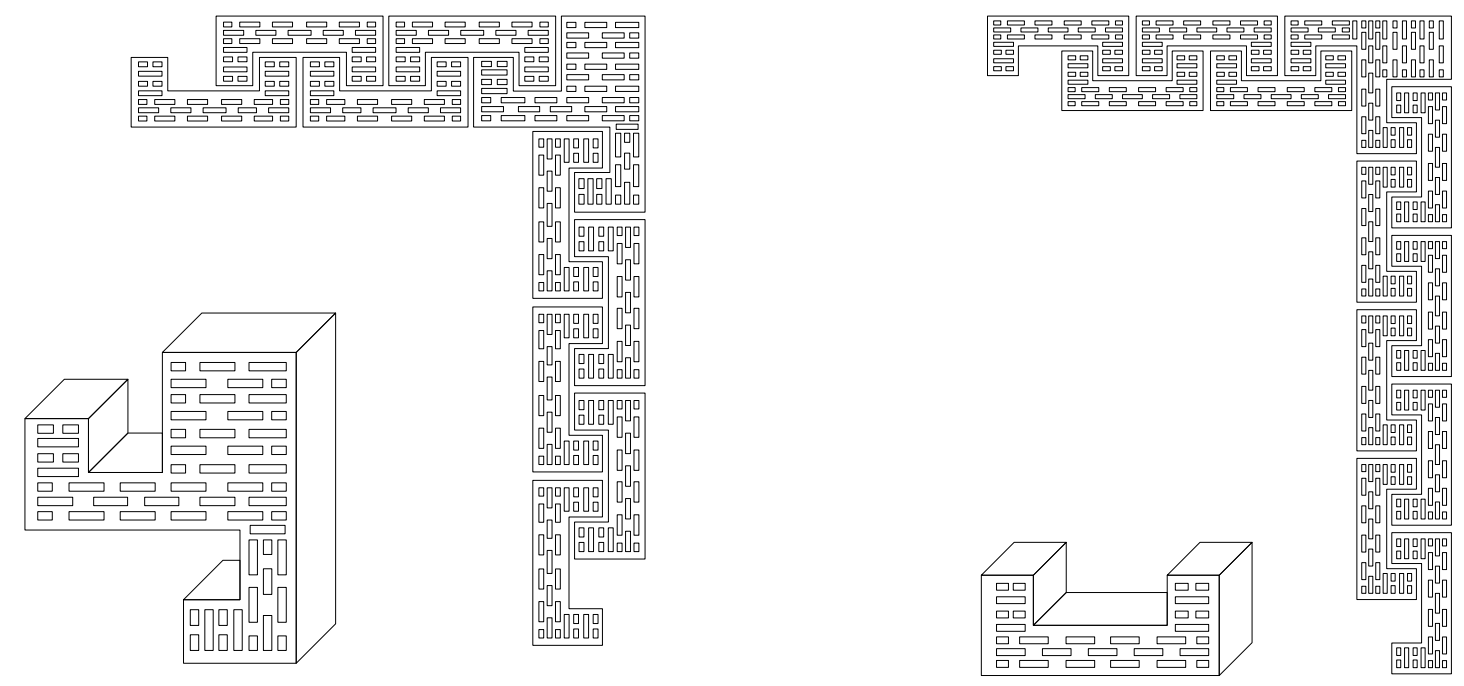

Figura 19 - Vista da geometria das unidades - Patente CN 102162285: CONCAVE CORNER BLOCKS AND MASONRY METHOD THEREOF - Data de depósito: 06/05/2011
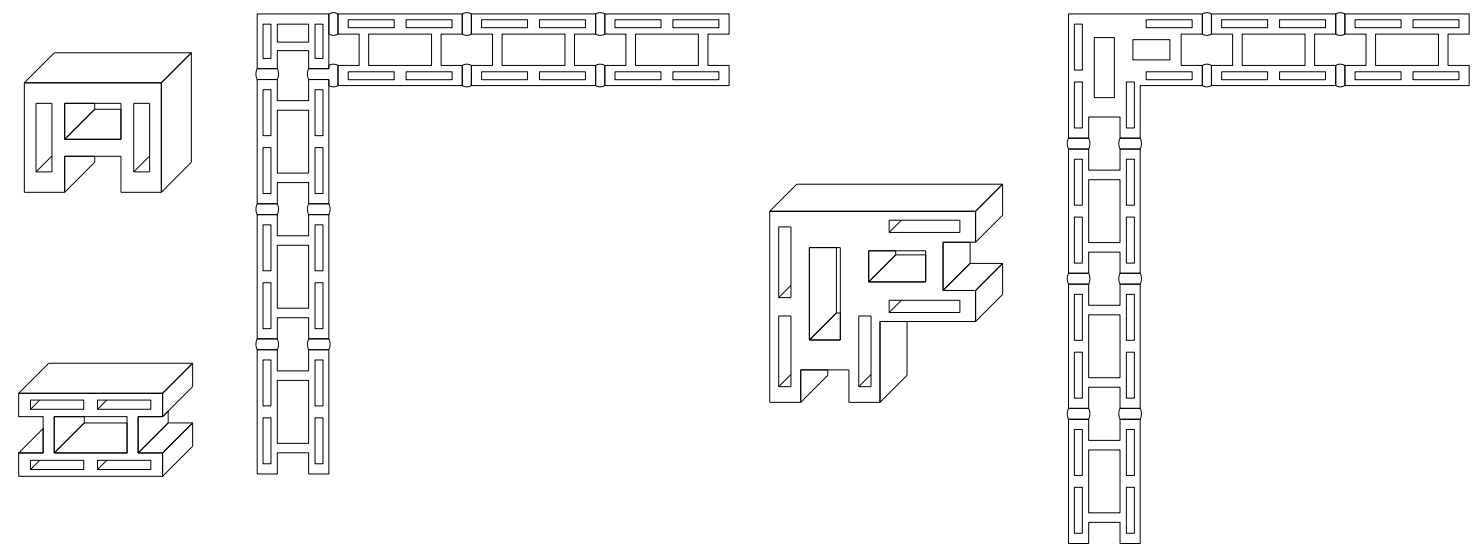

Figura 20 - Vista da geometria das unidades - Patente CN 102162285: MASONRY WALL SYSTEM - Data de depósito: $12 / 05 / 2006$
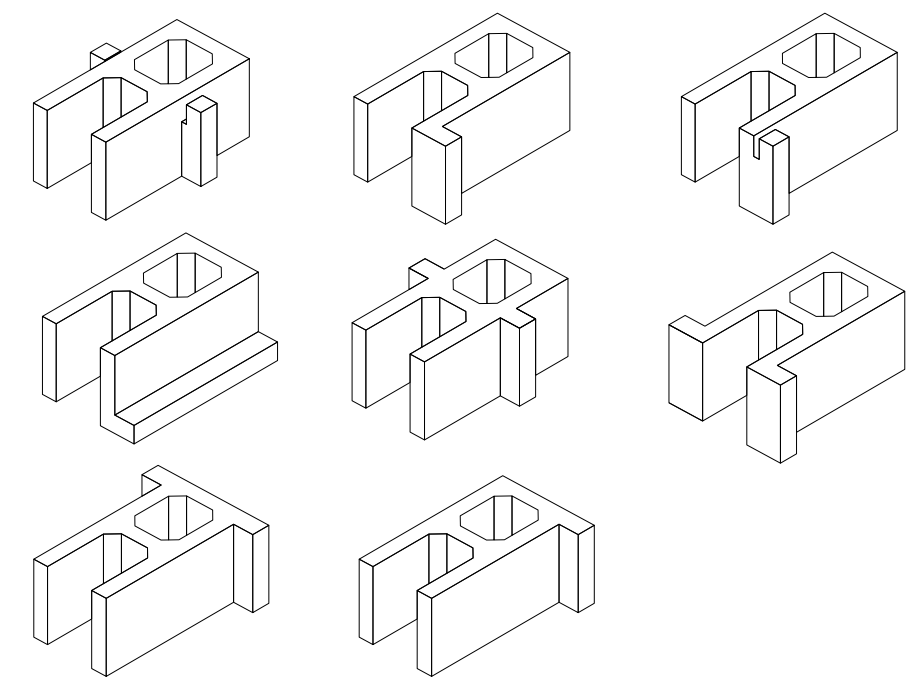

140 Mohamad, G.; Bavastri, E. Y. N.; Kirchhof, L. D.; Rizzatti, E.; Jantsch, A. C. A. 
A Figura 21 é uma patente desenvolvida para um bloco estrutural com abertura para a fixação da caixa elétrica. O bloco possui ranhuras nas paredes longitudinais que permitem sua quebra e fixação da caixa elétrica.

\section{Novas geometrias para os blocos}

As características propostas em relação à geometria dos blocos devem propiciar a criação de um produto que permita a sobreposição das paredes transversais dos blocos, a fim de aumentar o desempenho à compressão da parede e criar facilidades para a execução desse sistema, principalmente para as alvenarias grauteadas e armadas. Na Tabela 4 são apresentadas as diferentes unidades, suas denominações, formatos e características técnicas dos componentes estruturais.

\begin{tabular}{l}
\hline \multicolumn{1}{c}{ DENOMINAÇÃO } \\
Unidade 1 \\
Bloco do tipo "A": unidade \\
principal do sistema \\
construtivo em alvenaria. Não \\
possui a parede transversal no \\
lado direito, e os vazados são \\
desproporcionais. Em vista \\
superior possui formato de A. \\
As paredes transversais e \\
longitudinais são maciças.
\end{tabular}


Tabela 4 - Denominações dos blocos, formato geométrico e características (Continuação)

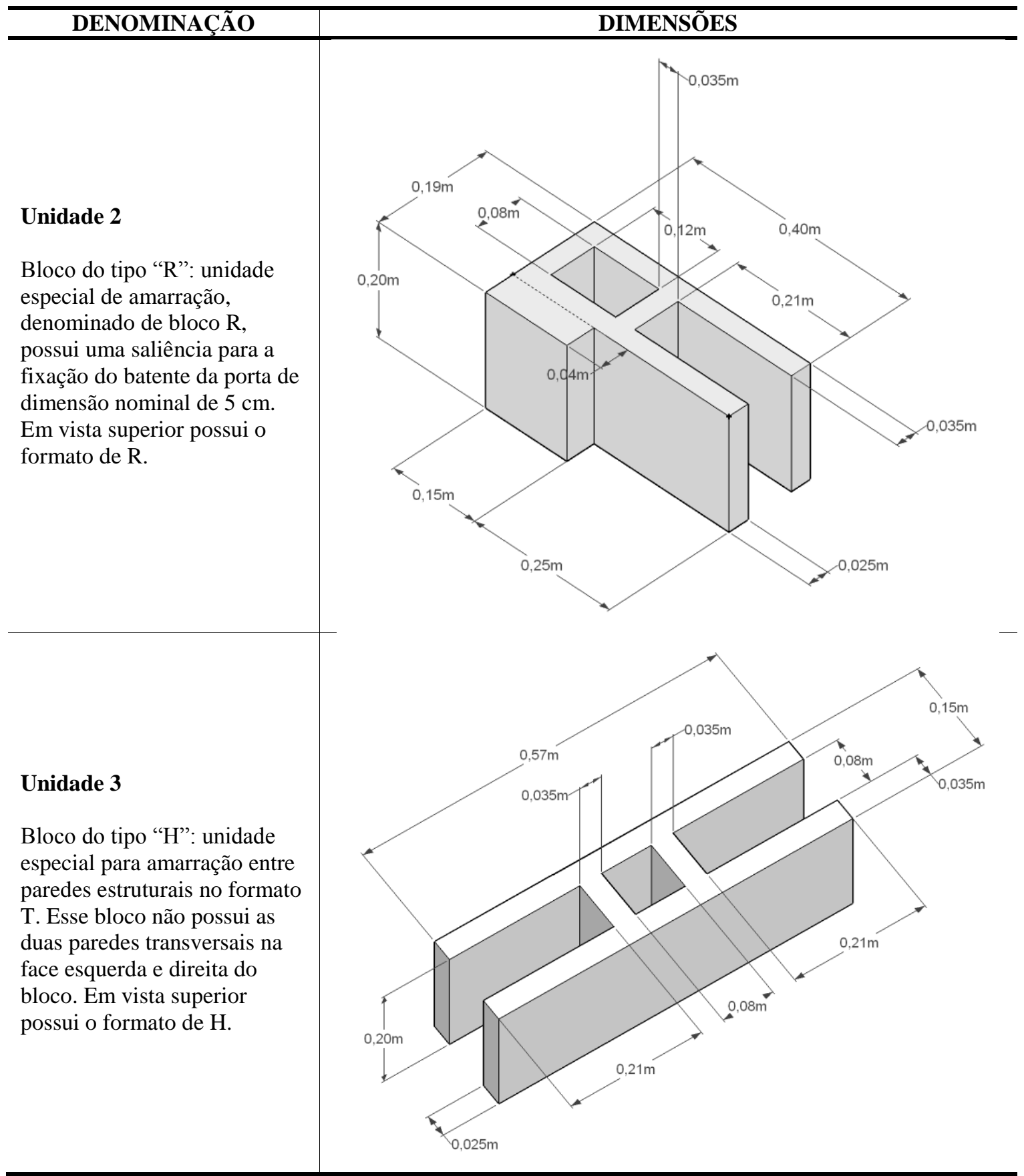

142 Mohamad, G.; Bavastri, E. Y. N.; Kirchhof, L. D.; Rizzatti, E.; Jantsch, A. C. A. 
Tabela 4 - Denominações dos blocos, formato geométrico e características (Continuação)

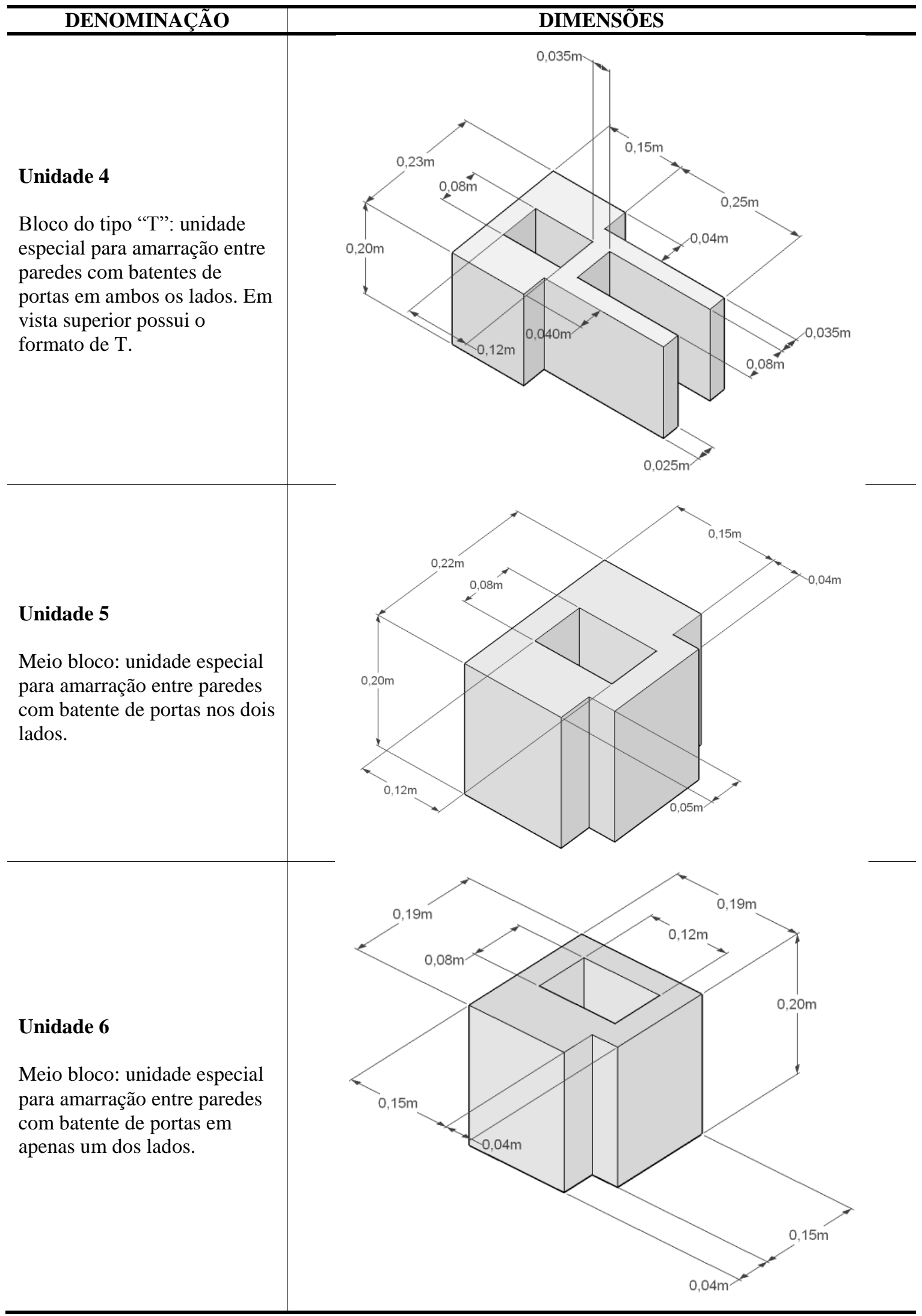


Tabela 4 - Denominações dos blocos, formato geométrico e características (Continuação)

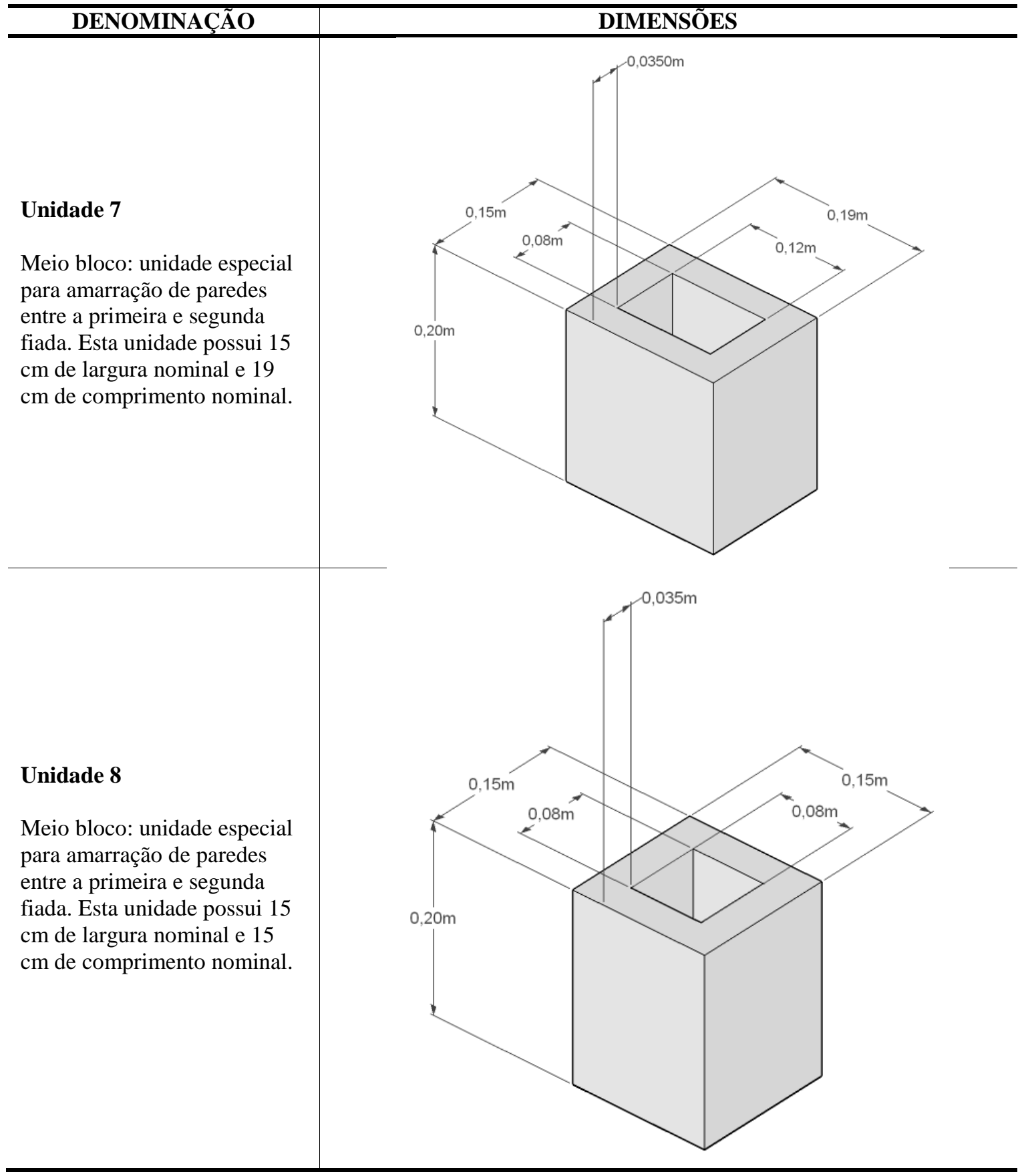

144 Mohamad, G.; Bavastri, E. Y. N.; Kirchhof, L. D.; Rizzatti, E.; Jantsch, A. C. A. 


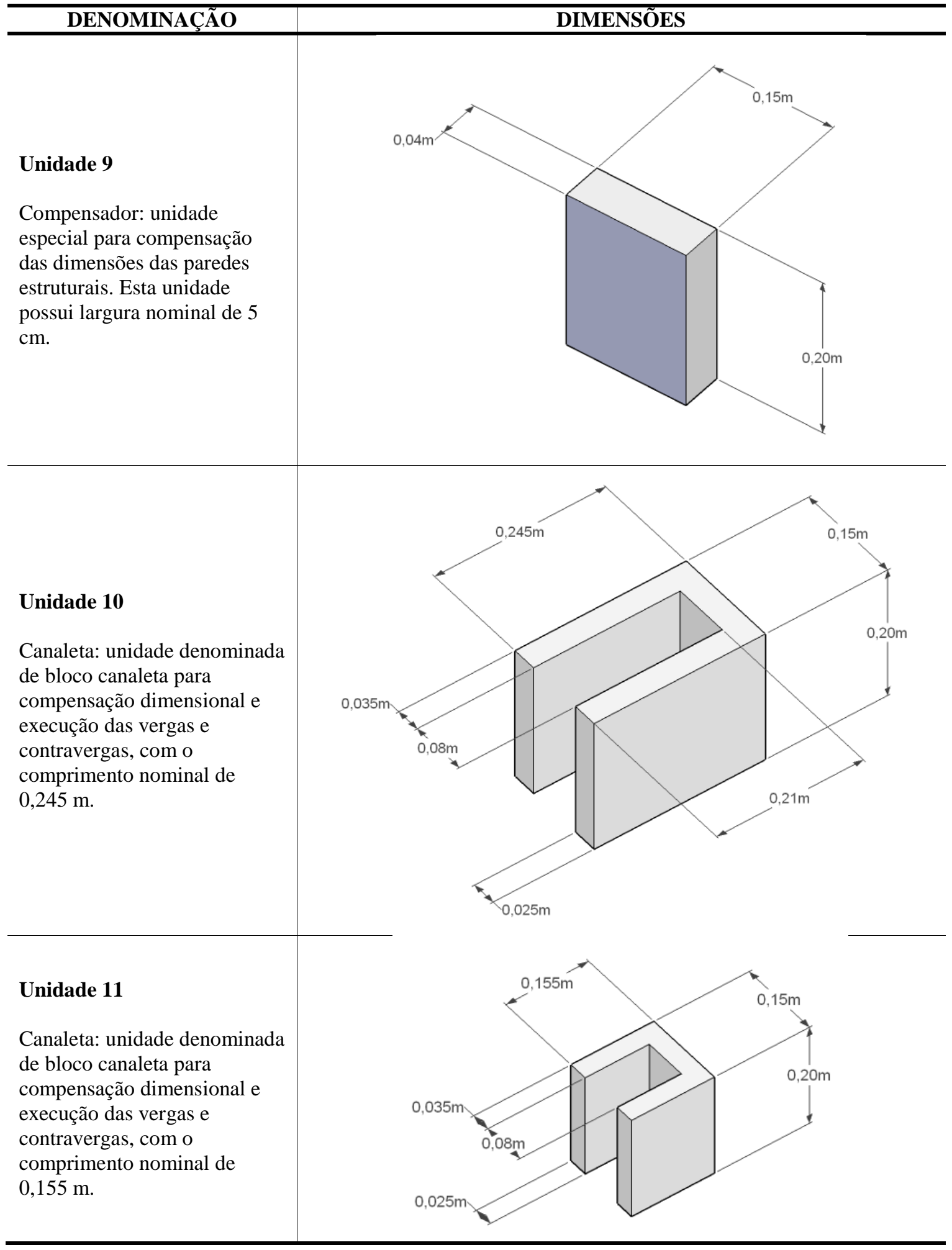

\section{Encontros entre as paredes estruturais}

Os principais encontros de paredes são as em X, L e T. A execução desses encontros deve ser realizada conforme mostram os detalhes em perspectivas das Figuras 22 a 24. A amarração em $\mathrm{X}$ é realizada com o emprego de dois blocos $\mathrm{H}$ na primeira e segunda fiadas. $\mathrm{O}$ bloco $\mathrm{H}$ da fiada superior amarra dois blocos $\mathrm{A}$ e um bloco $\mathrm{H}$ na fiada inferior (Figura 22). 
A amarração em L é realizada com o emprego de dois blocos A na primeira e na segunda fiada, e compensadores dimensionais. Podem, também, ser empregados dois blocos R. As disposições dos furos dos blocos na primeira e segunda fiada são intercaladas e em sentidos opostos, de forma a garantir as amarrações entre as paredes e as coincidências dos septos (Figura 23).

A amarração em T é realizada com o emprego de um bloco $\mathrm{H}$ na primeira fiada e três blocos $\mathrm{A}$ na segunda fiada. Na primeira fiada deve ser empregado um compensador dimensional para auxiliar a sobreposição das paredes superiores e inferiores. As disposições dos furos dos blocos na primeira e segunda fiadas são intercaladas e em sentidos opostos, de forma a garantir as amarrações entre as paredes e as coincidências dos septos (Figura 24).

\section{Controle tecnológico da resistência}

$\mathrm{Na}$ alvenaria estrutural exige-se que exista acompanhamento dos materiais e dos componentes, por meio dos ensaios laboratoriais de blocos, prismas e paredes. Como, normalmente, os ensaios em paredes têm maior complexidade e dificuldade de realização, a norma NBR 15961-2 (ABNT, 2011b) permite a utilização de prismas de dois blocos intercalados por uma junta de argamassa. Esse tipo de prisma sofre grande influência das interfaces de aplicação de carga, devido ao atrito, e não possui junta vertical de argamassa, o que torna a correlação entre a resistência da parede pelo prisma, muitas vezes, aproximada. Para o sistema aqui apresentado, o controle tecnológico do comportamento da parede deverá ser realizado por intermédio de ensaios à compressão de uma pequena parede de $60 \mathrm{~cm}$ x 60 $\mathrm{cm}$, bem mais simples de ser empregado, com três fiadas e com a presença da junta vertical de argamassa, como mostra a Figura 25. Esse tipo de componente é mais realístico com uma parede real, ainda mais no sistema que está sendo proposto, devido à coincidência das paredes longitudinais e transversais entre os blocos.

Figura 22 - Primeira e segunda fiadas da amarração em X
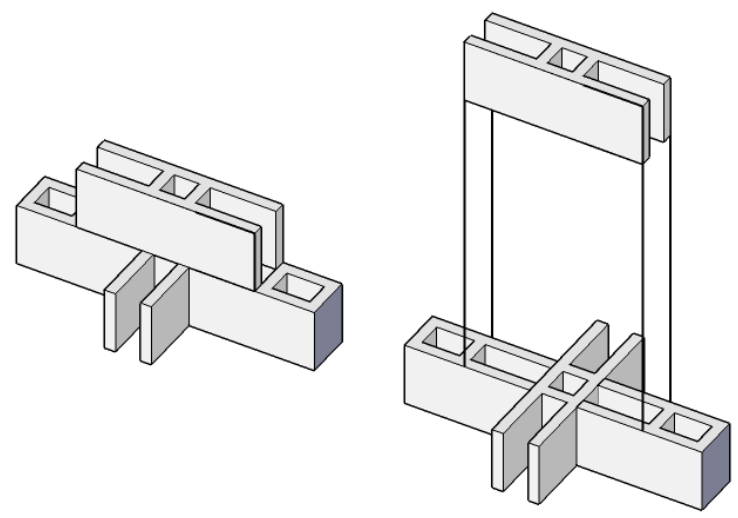

Figura 23 - Primeira e segunda fiadas da amarração em L
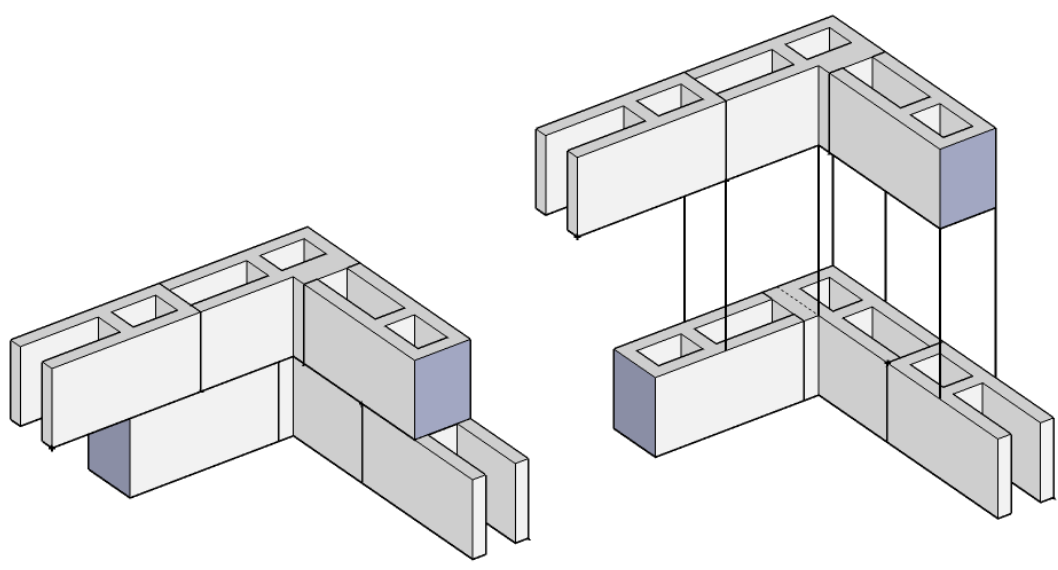

146 Mohamad, G.; Bavastri, E. Y. N.; Kirchhof, L. D.; Rizzatti, E.; Jantsch, A. C. A. 
Figura 24 - Primeira e segunda fiadas da amarração em T
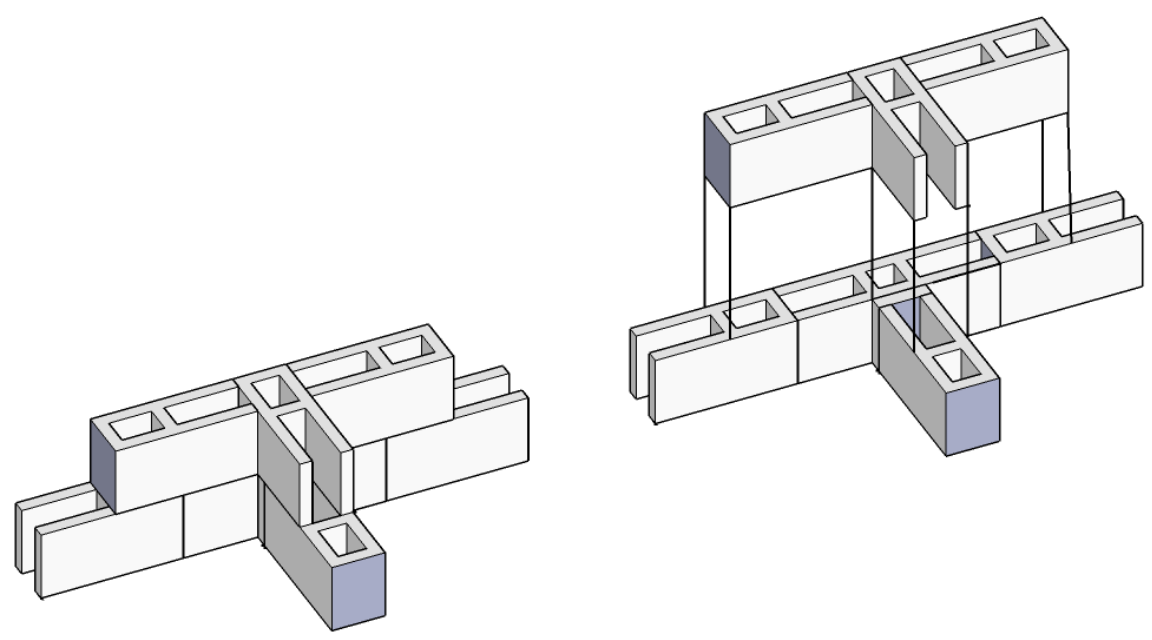

Figura 25 - Controle de qualidade por intermédio de ensaios de prismas

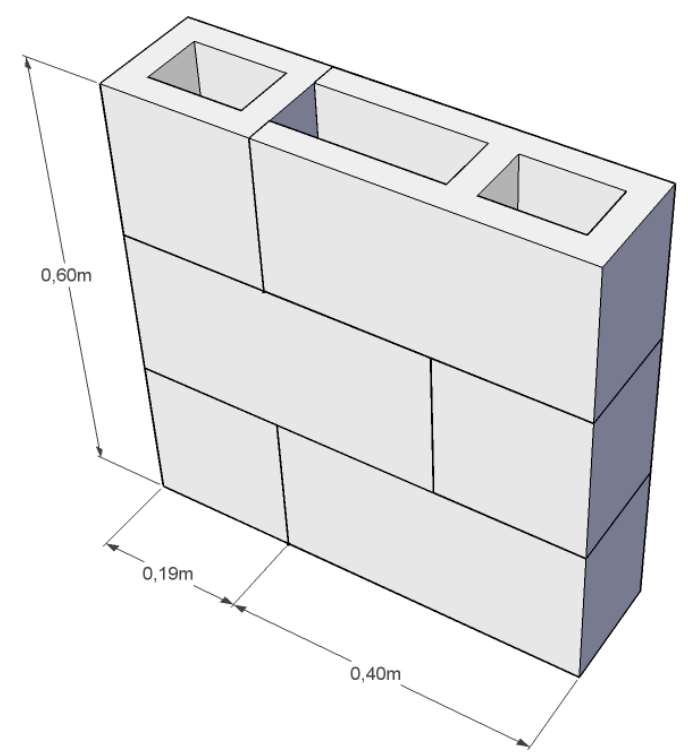

\section{Modulação das alvenarias estruturais}

Existe facilidade na execução das alvenarias com a presença de barras verticais em aço devido ao fato de o bloco não possuir uma das paredes laterais, com isso se diminuem os comprimentos de transpasses de barra e aumenta a produtividade na execução das paredes. A Figura 26 apresenta alguns detalhes construtivos.

A Figura 27 apresenta alguns aspectos construtivos de detalhamentos de encontros entre paredes com e sem a presença da abertura de porta, com as principais unidades construtivas necessárias para garantir a integridade estrutural do sistema.
Na Figura 28 são mostradas as vistas isométricas de três encontros entre paredes, sendo dois em L, com a presença da gola da porta, e um encontro em $\mathrm{T}$, em destaque, com a presença das unidades que compõem a respectiva amarração.

Na Figura 29 são mostradas as características modulares e dimensionais dos vãos para o emprego do sistema sem a utilização de compensadores dimensionais.

A Figura 30 apresenta a isométrica com os vãos modulares da primeira e segunda fiada das alvenarias. 
Figura 26 - Detalhamento do encontro das paredes com o posicionamento das armaduras

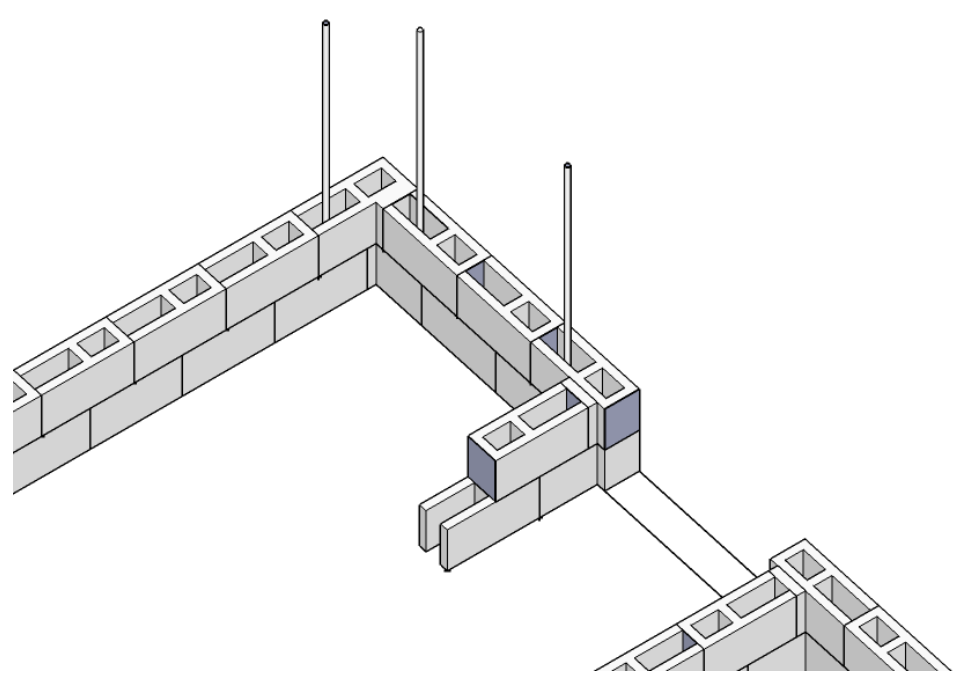

Isométrica da parede

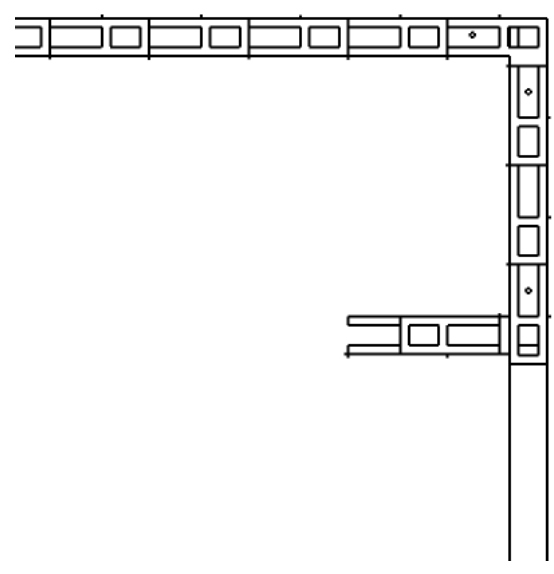

Vista superior da parede

Figura 27 - Encontro de paredes com o posicionamento de aberturas

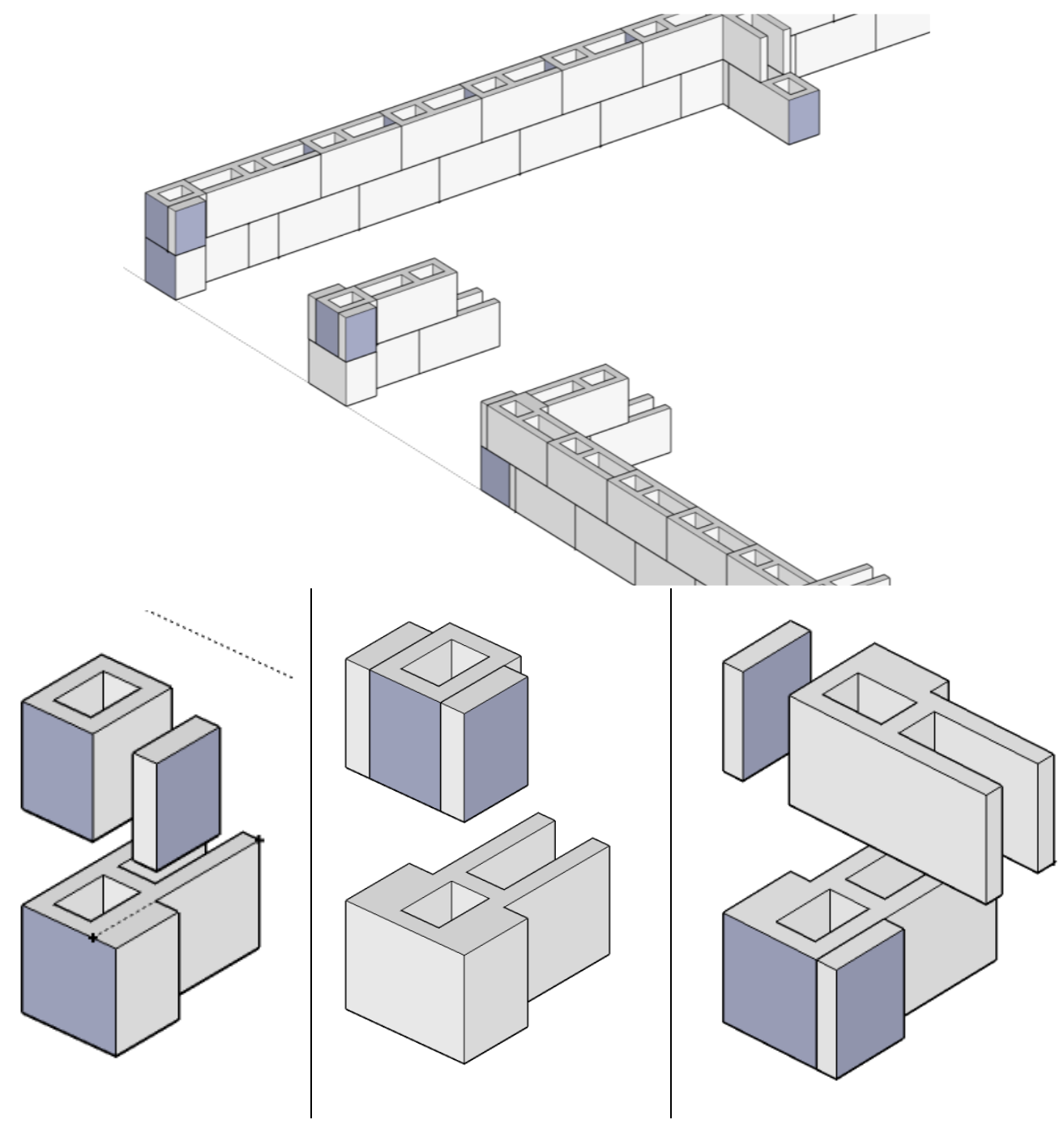

Nota: nessas uniões foram empregados as seguintes unidades: Bloco R, Meio Bloco, Compensador.

148 Mohamad, G.; Bavastri, E. Y. N.; Kirchhof, L. D.; Rizzatti, E.; Jantsch, A. C. A. 
Figura 28 - Encontro entre paredes em T
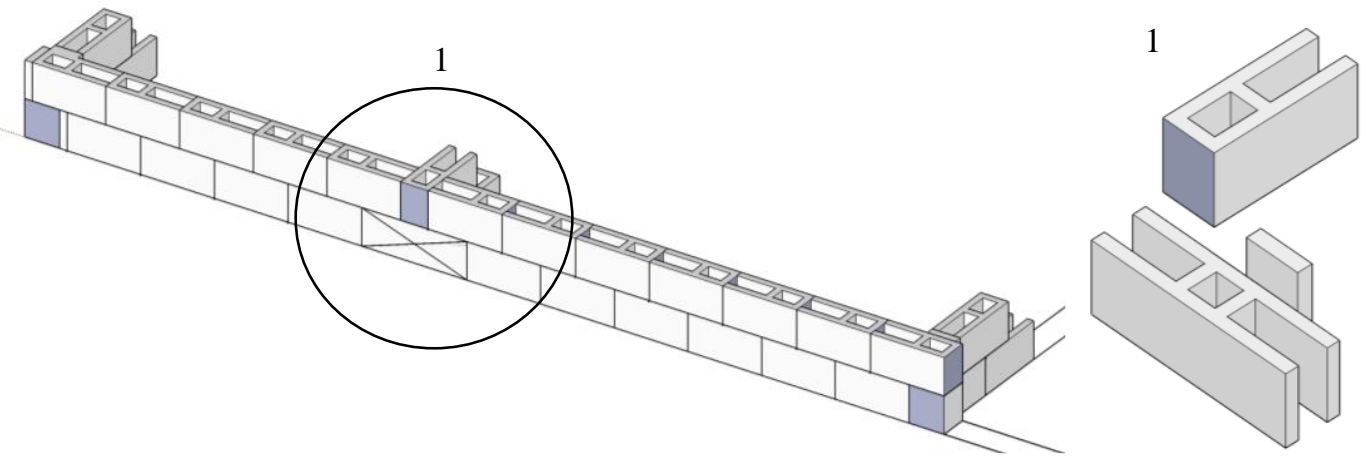

Nota: nessas uniões foram empregados unidades $\mathrm{H}$ e A e compensadores dimensionais.

Figura 29 - Características dos vãos modulares das alvenarias
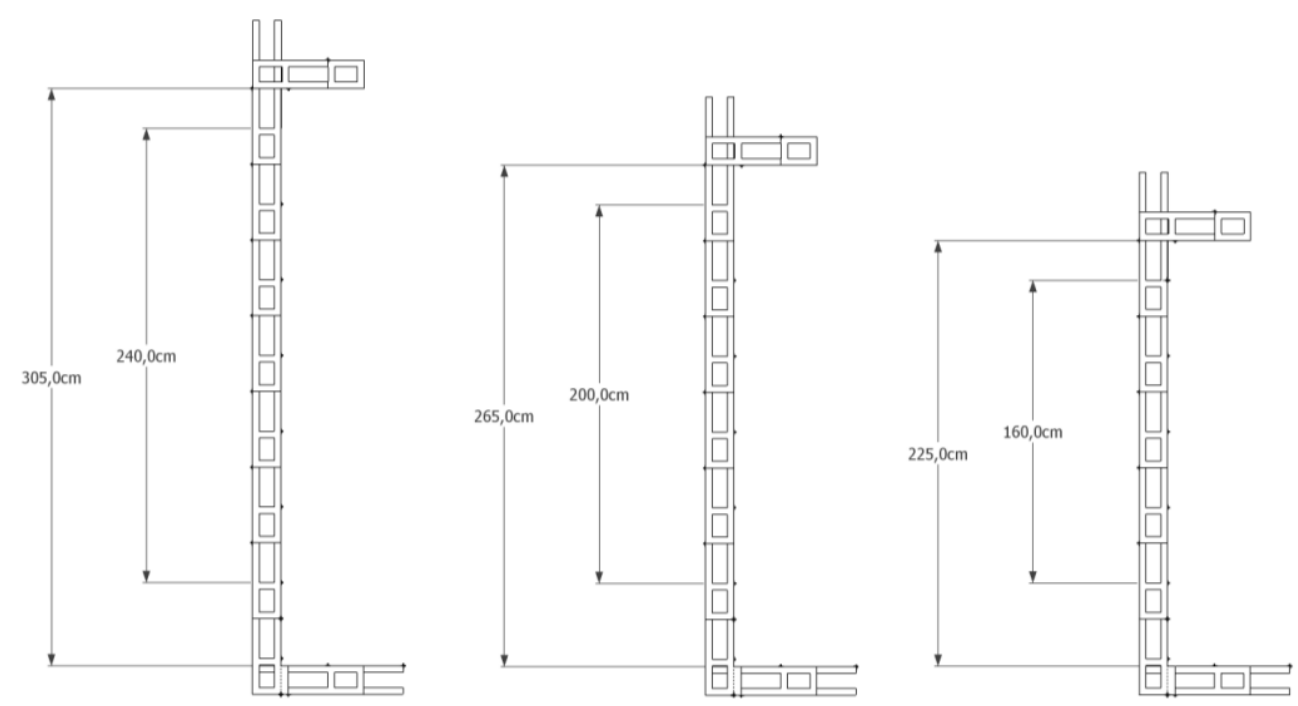

Figura 30 - Isométrica com a distribuição dos vãos modulares das alvenarias

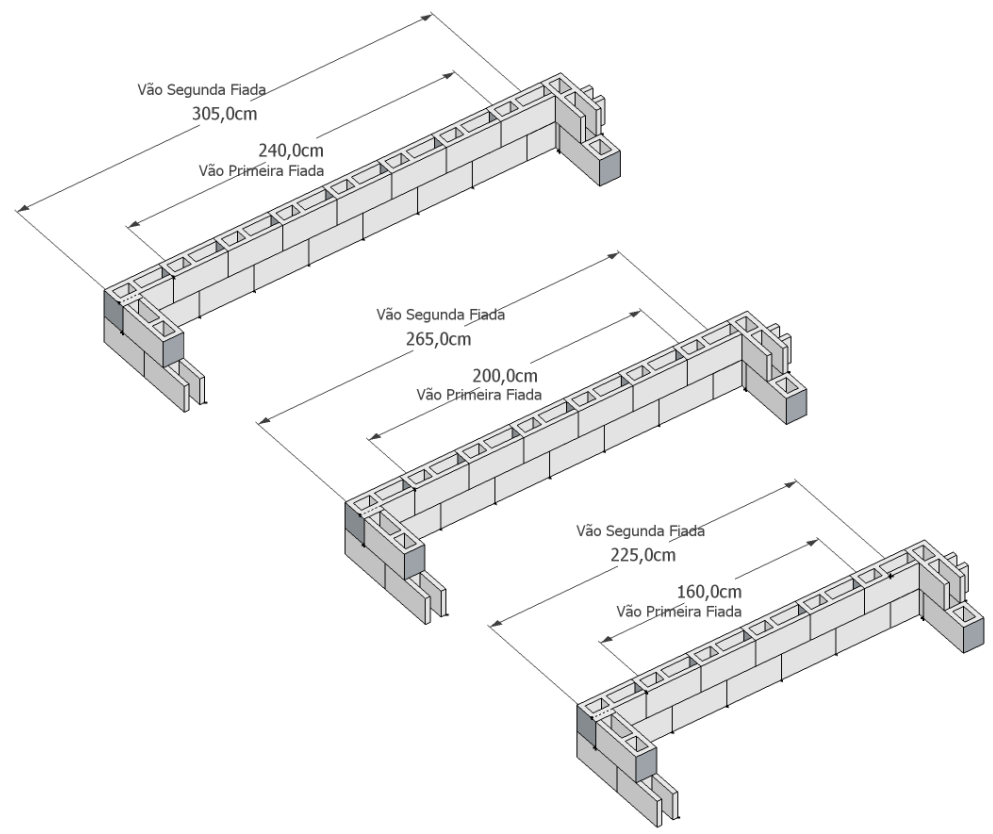

Desenvolvimento de uma nova concepção geométrica para os blocos de concretos não modulares para alvenaria 
Os vãos modulares entre uma amarração em L e T, tendo como referência o nó de amarração na primeira fiada e o vão do espaço, são apresentados na Tabela 5.

Na Figura 31 são mostradas as características modulares e dimensionais dos vãos para o emprego do sistema sem a utilização de compensadores dimensionais. Os vãos modulares entre as duas amarrações em L, tendo como referência o nó da amarração na primeira fiada e o vão do espaço necessário, são apresentados na Tabela 6.

Na Figura 32 é apresentada a vista superior e isométrica do lançamento da $1^{\mathrm{a}}$ e $2^{\mathrm{a}}$ fiadas dos blocos estruturais com o sistema construtivo proposto.

Tabela 5 - Vãos estruturais entre uma amarração em L e T

\begin{tabular}{c|c}
\hline \multicolumn{2}{c}{ VÃOS ESTRUTURAIS ENTRE UMA AMARRAÇÃO EM L e T (metros) } \\
\hline $1^{\text {a }}$ FIADA - Entre a amarração & $2^{\text {a }}$ FIADA - Vão do ambiente \\
\hline 1,20 - Equivale a 3 unidades & 1,85 \\
\hline 1,60 - Equivale a 4 unidades & 2,25 \\
\hline 2,00 - Equivale a 5 unidades & 2,65 \\
\hline 2,40 - Equivale a 6 unidades & 3,05 \\
\hline 2,80 - Equivale a 7 unidades & 3,45 \\
\hline 3,20 - Equivale a 8 unidades & 3,85 \\
\hline 3,60 - Equivale a 9 unidades & 4,25 \\
\hline $4,00-$ Equivale a 10 unidades & 4,65 \\
\hline $4,40-$ Equivale a 11 unidades & 5,05 \\
\hline $4,80-$ Equivale a 12 unidades & 5,45 \\
\hline
\end{tabular}

Figura 31 - Isométrica com a distribuição dos vãos modulares das alvenarias
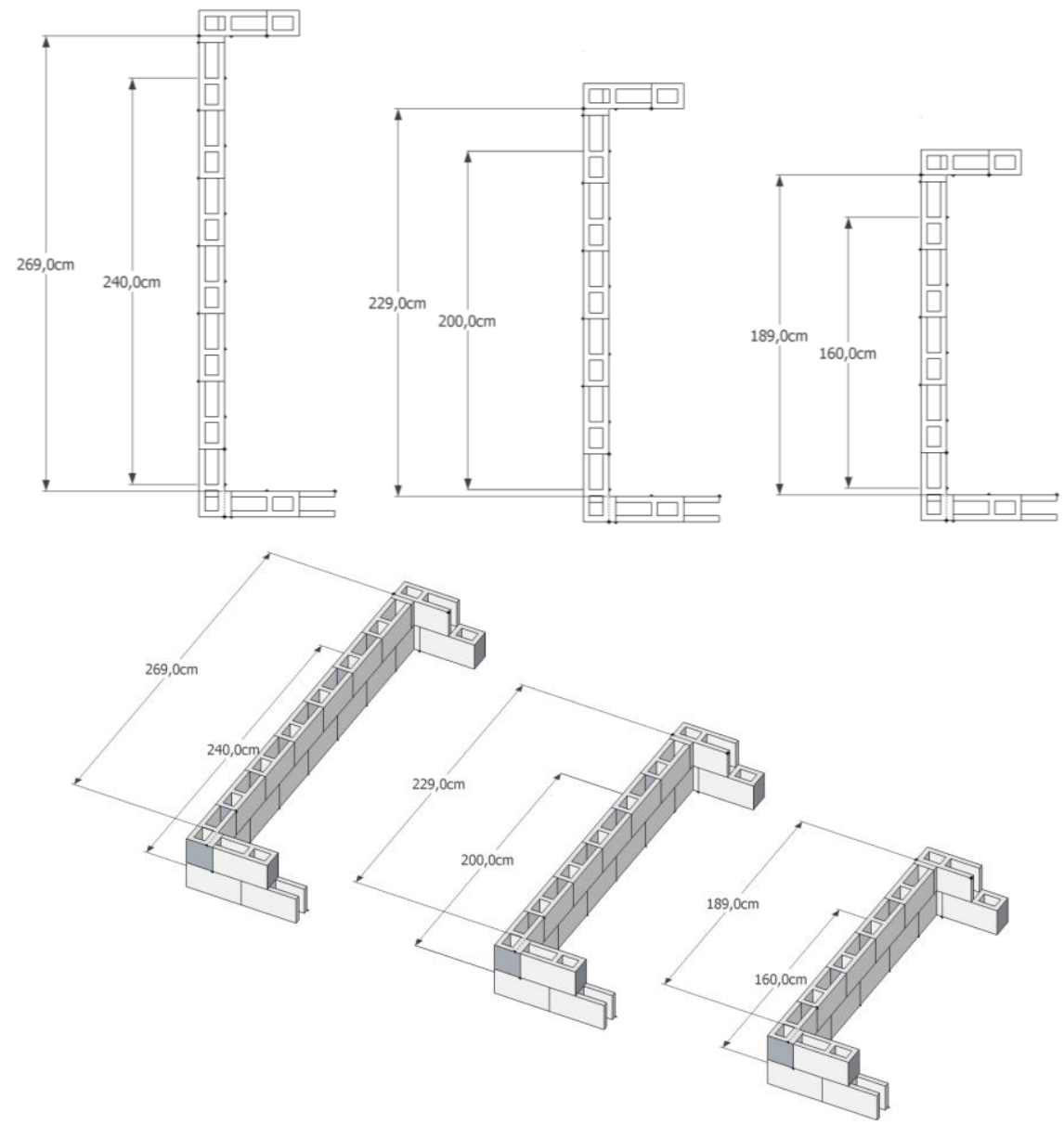

150 Mohamad, G.; Bavastri, E. Y. N.; Kirchhof, L. D.; Rizzatti, E.; Jantsch, A. C. A. 
Tabela 6 - Vãos estruturais entre duas amarrações em $\mathrm{L}$

\begin{tabular}{c|c}
\hline \multicolumn{2}{c}{ VÃOS ESTRUTURAIS ENTRE DUAS AMARRAÇÕES EM L (metros) } \\
\hline $\mathbf{1}^{\mathbf{a}}$ FIADA - Entre a amarração & $\mathbf{2}^{\mathbf{a}}$ FIADA - Vão do ambiente \\
\hline 1,20 - Equivale a 3 unidades & 1,49 \\
\hline 1,60 - Equivale a 4 unidades & 1,89 \\
\hline 2,00 - Equivale a 5 unidades & 2,29 \\
\hline 2,40 - Equivale a 6 unidades & 2,69 \\
\hline 2,80 - Equivale a 7 unidades & 3,09 \\
\hline 3,20 - Equivale a 8 unidades & 3,49 \\
\hline 3,60 - Equivale a 9 unidades & 3,89 \\
\hline 4,00 - Equivale a 10 unidades & 4,29 \\
\hline 4,40 - Equivale a 11 unidades & 4,69 \\
\hline 4,80 - Equivale a 12 unidades & 5,09 \\
\hline
\end{tabular}

Figura 32 - Vista superior e isométrica do lançamento da $1^{\mathrm{a}}$ e $2^{\mathrm{a}}$ fiadas

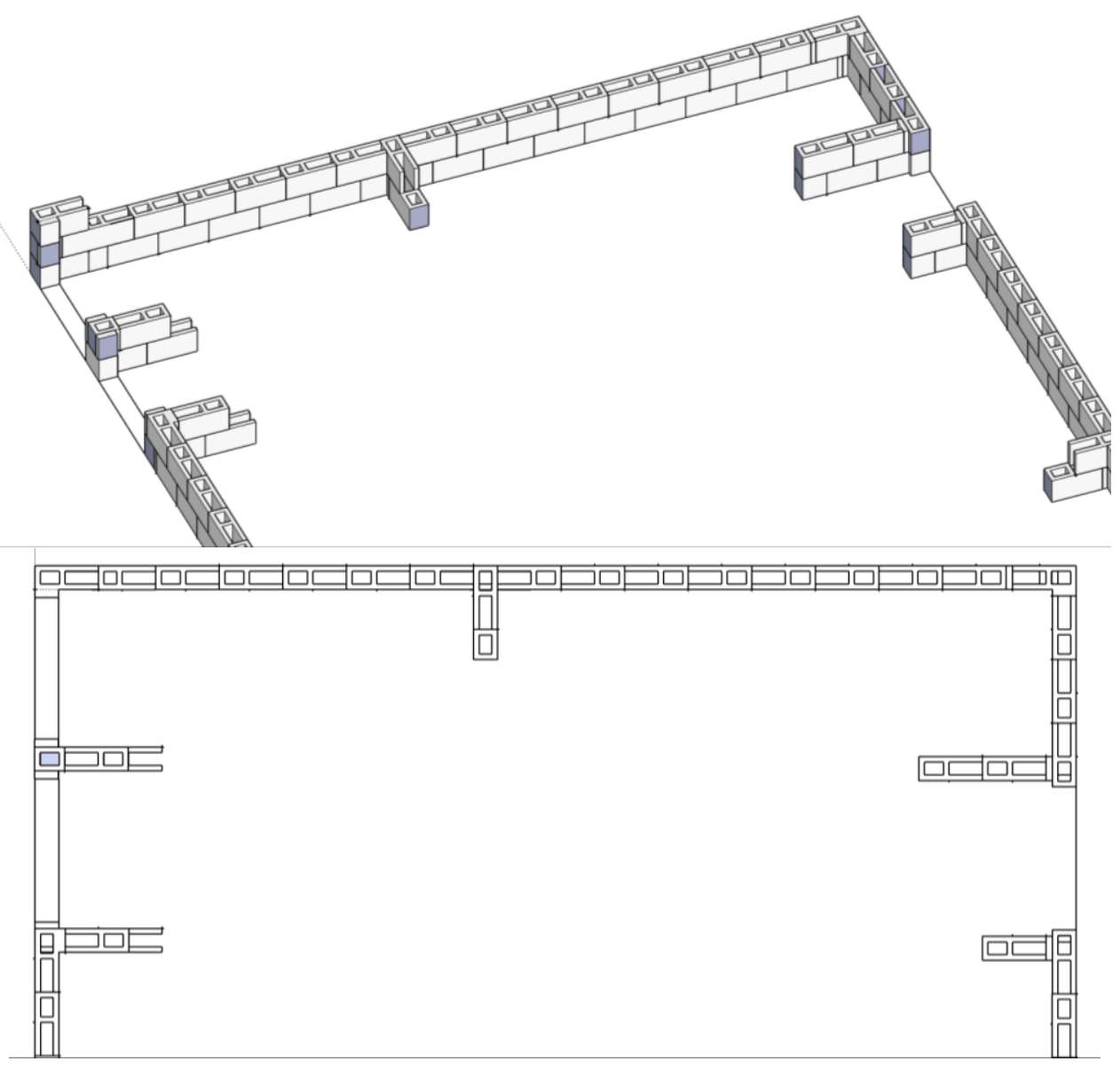

\section{Conclusões}

De acordo com os estudos desenvolvidos, pode-se chegar às conclusões a seguir.

Existe necessidade de inovações na área de desenvolvimento de produtos, principalmente para os blocos estruturais, que considerem as características de produção e desempenho estrutural.
As geometrias propostas são uma primeira etapa do projeto, que tem como sequência a modelagem numérica e a construção de protótipos em escala reduzida $1: 3$, a fim de verificar a viabilidade de produção e o desempenho estrutural, por meio da avaliação do fator de eficiência entre os componentes e os blocos.

Os diferentes tipos de blocos permitem composições entre eles e, com isso, a execução de 
todos os elementos necessários ao projeto das alvenarias, com a superposição vertical de todas as paredes transversais do bloco.

Os blocos propostos permitem a formação de colunas de grauteamento contínuas devido à superposição completa das paredes transversais.

Existem unidades especiais que permitem a execução das golas das portas com a utilização de compensadores.

A segunda fase desta pesquisa será a execução de ensaios à compressão em escala reduzida (1:3) dos blocos, prismas e pequenas paredes. O modelo geométrico dos blocos e o sistema executivo foram registrados no Instituto Nacional de Propriedade Intelectual (Inpi) sob o número BR 102012 0242524 , como patente de invenção.

\section{Referências}

ASSOCIAÇÃO BRASILEIRA DE CONSTRUÇÃO INDUSTRIALIZADA. Manual

Técnico de Alvenaria. São Paulo: ABCI, 1990.

ASSOCIAÇÃO BRASILEIRA DE NORMAS TÉCNICAS. NBR 15961-1: alvenaria estrutural: blocos de concreto: parte 1: projeto. Rio de Janeiro, 2011a.

\section{ASSOCIAÇÃO BRASILEIRA DE NORMAS}

TÉCNICAS. NBR 15961-2: alvenaria estrutural: blocos de concreto: parte 2: execução e controle de obras. Rio de Janeiro, 2011b.
ASSOCIAÇÃO BRASILEIRA DE NORMAS

TÉCNICAS. NBR 6136: bloco vazado de concreto simples para alvenaria estrutural: requisitos. Rio de Janeiro, 2014.

FRANCO, L. S. Racionalização Construtiva, Inovação Tecnológica e Pesquisas. In: CURSO DE FORMAÇÃO EM MUTIRÃO. São Paulo, EPUSP, 1996.

MOHAMAD, G.; LOURENÇO, P. B.; ROMAN, H. R. Study of the Compressive Strength of Concrete Block Prisms: stack and running Bond.

\section{Revista do IBRACON de Estruturas e}

Materiais, v. 4, n. 3, ago. 2011.

MOHAMAD, G. Construções em Alvenaria Estrutural: materiais, projeto e desempenho. São Paulo: Blucher, 2015

QUERO CONSTRUIR. Produto. Disponível em: <http://queroconstruir.meubox.com.br/detalhes.ph p?id_produto=34646\#.UkQxYtKThjs $>$ Acesso em: 26 set. 2013.

RIZZATTI, E. et al. Mechanical Behavior Analysis of Small Scale Modeling of Ceramic Block Masonry Structures: geometries effects. Revista do IBRACON de Estruturas e Materiais, v. 5, n. 5, out. 2012.

ROMAN, H. R. et al. Análise de Alvenaria Estrutural. Universidade Corporativa Caixa. GDA. NPC. UFSC. 1998.

\section{Gihad Mohamad}

Centro de Tecnologia | Universidade Federal de Santa Maria | Avenida Roraima, Prédio 07, Centro de Tecnologia, Camobi | Santa Maria RS - Brasil | CEP 97105-900 | Tel.: (55) 3220-8144 | E-mail: gihad.civil@gmail.com

\section{Elizabete Yukiko Nakanishi Bavastri}

Departamento de Engenharia Civil | Universidade Tecnológica Federal do Paraná | Rua Cristo Rei, 19, Campus Toledo, Vila Becker | Toledo - PR - Brasil | CEP 85902-490 | Tel.: (55) 3421-8400 Ramal 6838 | E-mail: elizabete_nakanishi@hotmail.com

\section{Larissa Degliuomini Kirchhof}

Centro de Tecnologia | Universidade Federal de Santa Maria | Tel.e: (55) 3220-8146 Ramal 8146 | E-mail: larissadk@gmail.com

\section{Eduardo Rizzatti}

Centro de Tecnologia | Universidade Federal de Santa Maria | E-mail: edu_rizzatti@yahoo.com.br

\section{Revista Ambiente Construído}

Associação Nacional de Tecnologia do Ambiente Construído

Av. Osvaldo Aranha, $99-3^{\circ}$ andar, Centro

Porto Alegre - RS - Brasil CEP $90035-190$

Telefone: +55 (51) 3308-4084

Fax: +55 (51) 3308-4054

www.seer.ufrgs.br/ambienteconstruido

E-mail: ambienteconstruido@ufrgs.br

152 Mohamad, G.; Bavastri, E. Y. N.; Kirchhof, L. D.; Rizzatti, E.; Jantsch, A. C. A. 